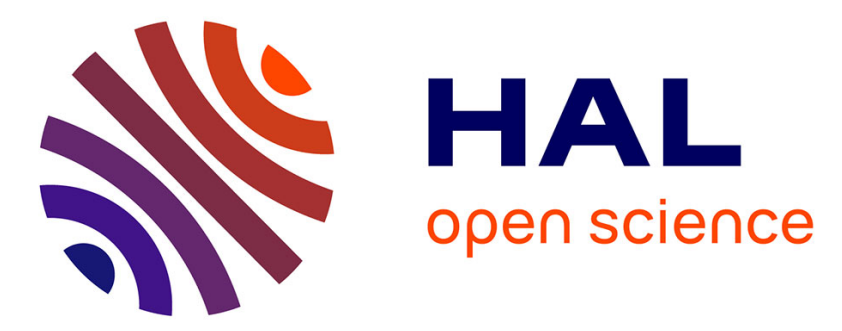

\title{
Individual and joint inversion of head and flux data by geostatistical hydraulic tomography
}

Behzad Pouladi, Niklas Linde, Laurent Longuevergne, Olivier Bour

\section{To cite this version:}

Behzad Pouladi, Niklas Linde, Laurent Longuevergne, Olivier Bour. Individual and joint inversion of head and flux data by geostatistical hydraulic tomography. Advances in Water Resources, 2021, 154, pp.103960. 10.1016/j.advwatres.2021.103960 . insu-03236469

\section{HAL Id: insu-03236469 \\ https://hal-insu.archives-ouvertes.fr/insu-03236469}

Submitted on 26 May 2021

HAL is a multi-disciplinary open access archive for the deposit and dissemination of scientific research documents, whether they are published or not. The documents may come from teaching and research institutions in France or abroad, or from public or private research centers.
L'archive ouverte pluridisciplinaire HAL, est destinée au dépôt et à la diffusion de documents scientifiques de niveau recherche, publiés ou non, émanant des établissements d'enseignement et de recherche français ou étrangers, des laboratoires publics ou privés. 


\section{Journal Pre-proof}

Individual and joint inversion of head and flux data by geostatistical hydraulic tomography

Behzad Pouladi, Niklas Linde, Laurent Longuevergne, Olivier Bour

PII:

DOI:

Reference:

To appear in:

Received date:

Revised date:

Accepted date:
S0309-1708(21)00115-9

https://doi.org/10.1016/j.advwatres.2021.103960

ADWR 103960

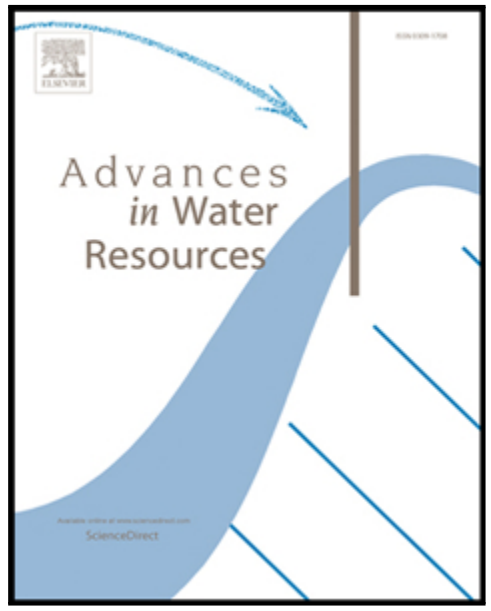

Please cite this article as: Behzad Pouladi, Niklas Linde, Laurent Longuevergne, Olivier Bour , Individual and joint inversion of head and flux data by geostatistical hydraulic tomography, Advances in Water Resources (2021), doi: https://doi.org/10.1016/j.advwatres.2021.103960

This is a PDF file of an article that has undergone enhancements after acceptance, such as the addition of a cover page and metadata, and formatting for readability, but it is not yet the definitive version of record. This version will undergo additional copyediting, typesetting and review before it is published in its final form, but we are providing this version to give early visibility of the article. Please note that, during the production process, errors may be discovered which could affect the content, and all legal disclaimers that apply to the journal pertain.

(C) 2021 Published by Elsevier Ltd. 
$7 \quad$ *Corresponding author.

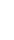

\section{Highlights}

\section{ABSTRACT}

\section{Individual and joint inversion of head and flux data by geostatistical hydraulic tomography}

Behzad Pouladi $^{1, *}$, Niklas Linde ${ }^{2}$, Laurent Longuevergne ${ }^{1}$, Olivier Bour ${ }^{1}$

${ }^{1}$ Univ Rennes, CNRS, Géosciences Rennes, UMR 6118, 35000 Rennes, France

${ }^{2}$ University of Lausanne, Institute of Earth Sciences, Lausanne, Switzerland

- Geostatistical inversion of head and flux data recorded under steady-state conditions

- For few observations, flux data is more informative than head data

- For many observations, the inversion results are comparable regardless of data type

- For equal number of observations, individual and joint inversion perform similarly

- The pumping borehole boundary condition affects individual, but not joint inversion

Hydraulic tomography is a state-of-the-art method for inferring hydraulic conductivity fields using head data. We employed geostatistical inversion using synthetically generated head and flux data individually and jointly in a steady-state experiment. We designed 96 inversion scenarios to better understand the relative merits of each data type. For the typical case of a small number of observation points, we find that flux data provide a better resolved hydraulic conductivity field compared to head data when considering data with similar signal-to-noise ratios. This finding is further confirmed by a resolution analysis. When considering a high number of observation points, the estimated fields are of 
similar quality regardless of the data type. In terms of borehole boundary conditions, the best setting for flux and head data are constant head and constant rate, respectively, while joint inversion results are insensitive to the borehole boundary type. When considering the same number of observations, the joint inversion of head and flux data does not offer advantages over individual inversions. When considering the same number of observation points and, hence, twice as many observations, the joint inversion performs better than individual inversions. The findings of this paper are useful for future planning and design of hydraulic tomography tests comprising flux and head data.

\section{KEYWORDS}

hydraulic tomography, groundwater flux, geostatistical inversion, principal component geostatistical analysis (PCGA), resolution analysis

\section{INTRODUCTION}

Knowledge of hydraulic conductivity distributions is essential for the management of water resources (Liu et al., 2020), solute transport predictions (Yeh, 1992; Jiménez, 2015) and designing remediation of contaminated sites (Fakhreddine et al., 2016). A variety of geophysical (Kowalsky et al., 2004; Revil et al., 2012; Slater, 2007) and hydraulic methods (Brauchler et al., 2003; Yeh and Liu, 2000; Zhu and Yeh, 2005), including tracer-based measurements (Doro et al., 2015; Jiménez et al., 2016; Somogyvári and Bayer, 2017), have been developed and employed for characterizing hydraulic properties (Lochbühler et al., 2013). In hydraulic flow methods, head data responses to hydraulic perturbations (pumping, tidal fluctuation, etc.) are measured at different locations across the aquifer. The recorded head data are then used to estimate the spatial distribution of hydraulic conductivity $(K)$ and storativity. A distinct advantage of hydraulic methods for imaging purposes is that the hydraulic response of an aquifer is directly related to its hydraulic parameters described by flow equations (Fakhreddine et al., 2016), while in most geophysical methods, the hydraulic properties are indirect and inferred from other estimated physical properties, thereby, requiring petrophysical relationships. We define $Y=\log _{10}(K)$ and assume that it can be described by a stationary multivariate Gaussian distribution. In other words, $Y$ is the $\log 10$ based hydraulic conductivity field.

Hydraulic tomography is one type of hydraulic method and has been the subject of many theoretical and numerical studies (Fienen et al., 2008; Luo et al., 2020; Yeh and Liu, 2000; Zha et al., 2018; Zhu and Yeh, 2005), laboratory experiments (IIIman et al., 2008, 2010; Liu et al., 2002, 2007; Yin and IIIman, 2009; Zhao et al., 2016), and field studies (Berg and Illman, 2015, 2013, 2011; Bohling et al., 2007; Brauchler et al., 2013, 2011, 2010, 2003; Cardiff et al., 2009, 2013; Cardiff and Barrash, 2011; Fischer et al., 2017; Gottlieb and Dietrich, 1995; Huang et al., 2011; Klepikova et al., 2013; Kuhlman et al., 2008; Paradis et al., 2016, 2015; Sun et al., 2013; Tosaka et al., 1993). However, hydraulic tomography based on head data alone has limitations. One limitation is inherent to the underlying potential-field physics as measured head data are spatially averaged due to the diffusive nature of pressure disturbances created during the test (Bohling and Butler Jr, 2010). This averaging results in tomographic estimates displaying a high degree of smoothing compared to the actual aquifer property fields. This smearing may lead to 
degraded predictions for transport problems. It should be noted that the smoothing would only appear in a single, regularized solution. However, if one uses stochastic methods, one should be able to represent the stochastic nature of the underlying actual aquifer property fields. Furthermore, some authors have included geological data as a priori information to overcome this issue (Luo et al., 2017; Zha et al., 2017; Zhao and IIIman, 2018). Another limitation appears in applying hydraulic tomography in high conductivity aquifers as hydraulic tests lead to small drawdown values, implying high relative uncertainty of the measured head perturbations and correspondingly low signal-to-noise ratio data. Adding other types of non-redundant data in hydraulic tomography can help to better image the subsurface (Mao et al., 2013; Yeh et al., 2015). In this regard, Zha et al. (2014) demonstrated the usefulness of flux data (specific discharge) for hydraulic tomography in a 2D synthetic fractured media mimicking a field site in Mizunami, Japan. Estimated mean, variance, and correlation length of the $Y$ field were applied as prior information to the inversion model. Using the cross-correlation approach (Zha et al., 2014), they showed that head and flux contribute differently to the $Y$-field reconstruction. They claimed that inversion of head data collected with known pumping rate can result in representative $Y$-field estimates even if the initial guess is incorrect. For flux data, they find that the final $Y$-field estimate is dependent on the initial guess. Their synthetic work showed that using flux data with head data improves the estimation of $Y$-field values and the fracture distribution. In another study, Tso et al.( 2016) performed numerical test studies on a 3D model mimicking the aquifer at the North Campus Research site in Waterloo, Canada. They simulated pumping in this porous aquifer and measured head data and flux data at different locations. Then, head and flux data were subjected to inversion, considering different types of prior information. They showed that using flux data jointly with head data can enhance hydraulic conductivity estimates. Furthermore, they found out that the estimated hydraulic conductivity field is less affected by an inadequate prior model when nonredundant flux data are used to supplement the head data.

Until recently, measurements of groundwater fluxes in the field were limited to local and timeconsuming measurements. The most popular technique for quantifying groundwater flux in the field was based on dilution tests (Drost et al., 1968; Jamin et al., 2015; Schneider et al., 2019), where the dilution of an injected tracer inside a screened borehole or within packers is used to estimate the horizontal groundwater flux. Other approaches, such as the colloidal borescope (Kearl, 1997), the point velocity probe (Labaky et al., 2007) or the in-situ permeable flow sensor (Ballard, 1996), can also measure the horizontal groundwater flux. A comprehensive review of the groundwater velocity measurement approaches is provided by Devlin (2020). Nevertheless, boreholes disturb the flow field and affect the measurements; hence, the measured values may not represent the real flux values. Moreover, these methods are in general limited to local measurements and do not provide in most cases the spatial variability of groundwater fluxes.

The recent advent of Fiber Optic Distributed Temperature Sensors (FO-DTS) has led to new possibilities for measuring groundwater discharge with unprecedented spatial resolution (des Tombe et al., 2019; Simon et al., 2021, del Val et al., 2021). FO-DTS is a distributed sensor type that allows measurements of temperature all along the fiber optic cable. FO-DTS can be employed in both passive and active modes. In passive mode, the temperature of the fiber optic is measured without any external 
forcing, while in active mode, a heat source is added to the fiber optic cable by using a heating element located very close to the fiber optic cable or by using a heating fiber optic cable. Active-DTS have been developed, for instance, for measuring borehole flows (Read et al., 2014), wind speed (Sayde et al., 2015), and for characterizing groundwater fluxes in fractured media (Maldaner et al., 2019). Recently, it has also been used for measuring groundwater discharge in sedimentary aquifers; the FO cable typically being installed by the direct push method (Bakker et al., 2015; des Tombe et al., 2019) or along boreholes (del Val et al., 2021). In this case, the buried cable is in direct contact with the ground with minimum subsurface perturbations. Simon et al. (2021) showed that active-DTS can be used for measuring both sediment thermal conductivities and groundwater fluxes on a large range of values with excellent accuracy (with errors of less than $10 \%$ for groundwater flux in the range of $10^{-5}$ to $10^{-3} \mathrm{~m} / \mathrm{s}$ ). The principle of such an experiment (Figure 1) is to monitor the temperature evolution with time, which depends on the surrounding area's thermal properties and also groundwater fluxes that limits the temperature rise. Typically, the slope of the temperature rise in the conduction regime (with time in logarithmic scale) is inversely proportional to thermal conductivity while the greater the groundwater fluxes, the lower the temperature at stabilization. The temperature evolution with time may be easily interpreted to estimate groundwater fluxes through an analytical solution or by using a graphical analysis (Simon et al., 2021). The application of Active FO-DTS for flux measurements is currently limited to shallow and unconsolidated aquifers due to limitations in deployment by the direct push method.

(a)
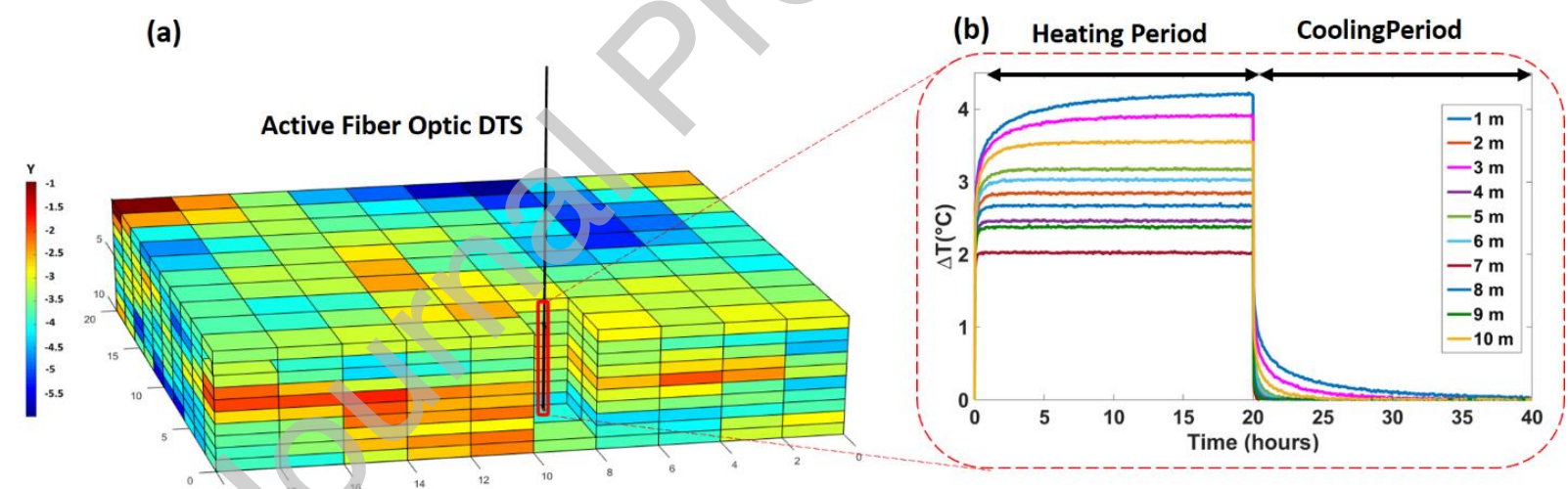

(c)

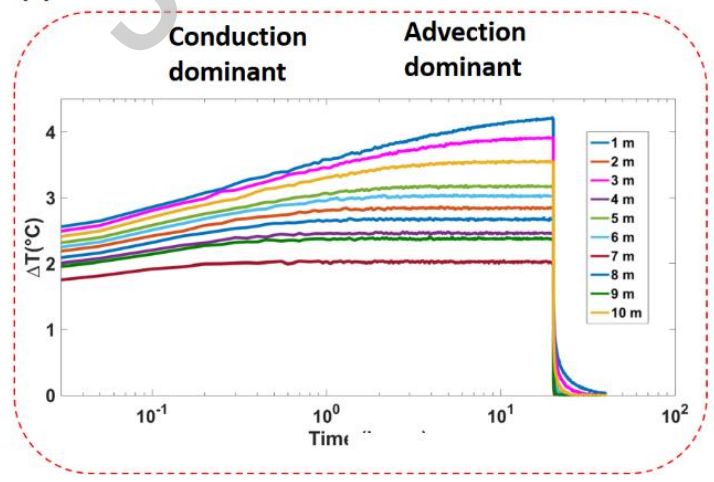

(d)

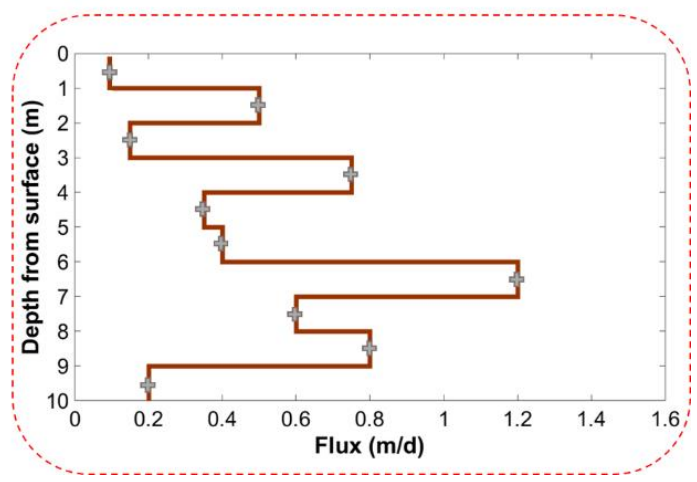


Figure 1: Schematic description of how Active FO-DTS can be used to infer a groundwater flux profile with depth. (a) An Active Fiber Optic Cable is deployed vertically into the ground in close contact with the formation. (b) The cable is heated (active mode), and the cable temperature during the heating (first 20 hours) and cooling periods (from 20 to 40 hours) is measured. Each curve corresponds to one-point measurement along the FO-cable. (c) In semi-logarithmic plot, the slope of the temperature profile is used to estimate the thermal conductivity while the temperature at stabilization is dependent on groundwater fluxes (Simon et al., 2021). (d) Measured temperature data along the fiber optic cable are converted to a flux profile with depth, with each "+" sign indicate one datum.

New advances in distributed sensing of local groundwater flux make it an appealing data source for independent inversion or joint inversion with hydraulic head. This present study assumes that groundwater fluxes can be inferred from such above-mentioned techniques at a prescribed spatial resolution and accuracy. It is worth mentioning that measuring head data is more accurate and easier than flux data. However, Active FO-DTS and new developments in the data analysis provide promising result for measurement of the flux along FO cables. Here, we limit ourselves to a 2-D study assuming constant groundwater flux in depth. Using a geostatistical hydraulic tomography approach, we then address the benefits and drawbacks of using either head or flux data individually or jointly. More specifically, we address the following questions.

(1) For an equal number and locations of flux and head data, which data type leads to the best reconstruction of hydraulic conductivity?

(2) How does the number of observations affect the inversion results?

(3) How does inversion performance for the different data types vary with the hydraulic conductivity field variance?

The paper is structured into six sections. Section 2 presents the geostatistical inversion method and the forward model employed. In section 3 , we describe the hydraulic conductivity test model used for our analysis. In sections 4 and 5, we present and discuss the main results, respectively, and section 6 concludes the paper.

\section{METHODS}

The Principal Component Geostatistical Approach (PCGA) is a computationally-efficient geostatistical inversion method (Lee and Kitanidis, 2014). PCGA uses the main principal components of the prior model covariance matrix for model parameterization and corresponding estimates of the Jacobian (sensitivity matrix). The resulting model reduction from a model of many gridded elements to a lower number of retained principal components leads to smaller matrices to invert and fewer sensitivities to estimate, implying less computational costs than full inversions. This method has been employed extensively in recent years (Fakhreddine et al., 2016; Fischer et al., 2017; Kang et al., 2017; Lee et al., 
2018; Soueid Ahmed et al., 2016). In this study, we use PCGA combined with the Matlab Reservoir Simulation Toolbox (MRST) that simulates fluid flow in porous media (forward model) to perform inversion of head and flux data.

\subsection{Inverse model}

Inferring properties of subsurface media (storage, hydraulic conductivity) from error-contaminated and sparse observed data (head data, flux data, etc.) is an inverse problem and can be formulated as follow:

$\mathbf{d}=f(\mathbf{m})+\mathbf{\eta}$,

where $\mathbf{d}, f(-), \mathbf{m}$ and $\boldsymbol{\eta}$ refer to measured data, forward model, model parameters and errors, respectively. The forward model refers here to a non-linear operator solving a set of differential equations numerically to describe the relationship between model parameters and data. When considering the joint inversion of two different data type $\left(\mathbf{d}_{1}\right.$ and $\left.\mathbf{d}_{2}\right)$, the formulation is as follow:

$$
\left[\begin{array}{l}
\mathbf{d}_{1} \\
\mathbf{d}_{2}
\end{array}\right]=f(\mathbf{m})+\left[\begin{array}{l}
\mathbf{n}_{1} \\
\mathbf{n}_{2}
\end{array}\right]
$$

From a mathematical point of view, the inverse problem is often ill-posed and the solution is nonunique, implying that additional information (e.g., a prior model) is required to obtain unique and physically-meaningful results. The prior model inferred based on the available information about the subsurface media. In this work, the same prior model is used throughout to avoid the effect of the prior model on the comparisons of final results. Here, the subsurface is described as a multi-Gaussian stationary field with known statistical properties and a superimposed deterministic trend. In the presence of a multivariate Gaussian prior model and error distribution, it is common to formulate the inverse problem in terms of an exploration of the maximum a posteriori (MAP) estimate and its variance. In such a setting, the solution of the inverse problem is obtained by maximizing a posterior probability density function (maximizing the term in bracket) expressed by using Bayes' theorem as follow:

$\pi_{\text {post }}(\mathbf{m} \mid \mathbf{d}) \sim \exp \left[\frac{-1}{2}(f(\mathbf{m})-\mathbf{d}) \mathbf{C}_{\mathrm{d}}^{-1}(f(\mathbf{m})-\mathbf{d})+\frac{-1}{2}\left(\mathbf{m}-\mathbf{m}_{\text {prior }}\right) \mathbf{C}_{\mathrm{m}}^{-1}\left(\mathbf{m}-\mathbf{m}_{\text {prior }}\right)\right]$

where $\mathbf{C}_{\mathrm{m}}$ and $\mathbf{C}_{\mathrm{d}}$ are the a priori model covariance and data covariance matrix, respectively (Kitanidis, 1995).

Geostatistical methods have been widely used and proven to be efficient for hydraulic tomography purposes (IIIman et al., 2015). The iterative optimization process estimates the model parameters. The solution at $(i+1)^{\text {th }}$ iteration is calculated as:

$\mathbf{m}_{i+1}=\mathbf{X} \boldsymbol{\beta}_{i}+\mathbf{C}_{\mathrm{m}} \mathbf{J}_{i}{ }^{\top} \boldsymbol{\varepsilon}_{i}$

where $\mathbf{X}$ is a known matrix, and $\boldsymbol{\beta}$ is an unknown vector used to determine linear trends that is inferred along with $\boldsymbol{\varepsilon}$ by solving the system of equations below. In this equation, $\mathbf{X}$ is a trend matrix and $\boldsymbol{\beta}$ is trend 
vector. Here J represents the Jacobian matrix describes the sensitivity of the forward model output (at observation points) with respect to the unknown model parameters.

$$
\left[\begin{array}{cc}
\mathbf{J}_{i} \mathbf{C}_{\mathrm{m}} \mathbf{J}_{i}{ }^{T}+\mathbf{C}_{\mathrm{d}} & \mathbf{J}_{i} \mathbf{X} \\
\left(\mathbf{J}_{i} \mathbf{X}\right)^{T} & 0
\end{array}\right]\left[\begin{array}{l}
\boldsymbol{\varepsilon}_{i} \\
\boldsymbol{\beta}_{i}
\end{array}\right]=\left[\begin{array}{c}
\mathbf{d}-f\left(\mathbf{m}_{i}\right)+\mathbf{J}_{i} \mathbf{m}_{i} \\
0
\end{array}\right]
$$

\subsubsection{Principal Component Geostatistical Approach}

Calculating the Jacobian matrix $(\mathrm{J})$ used in equations (4) and (5) for high-dimensional problems often requires a very high computational effort. Lee and Kitandis (2014) proposed the Principal Component Geostatistical Approach (PCGA), which uses a low-rank approximation of the prior covariance via principal component analysis and avoids forming the Jacobian explicitly for products of the Jacobian matrix and eigenvalues (equations (7) and (8)) by using a finite difference approximation (equation (9)). This results in a faster inversion process of high accuracy, provided that an adequate number of principal components are retained. The terms that are used for geostatistical inversion in equation (5) are approximated through the $P$ largest principal components as follow:

$\mathbf{C}_{\mathrm{m}} \approx \mathbf{C}_{\mathrm{m} P}=\sum_{i i=1}^{P}\left(\boldsymbol{s}_{i i}\right)\left(\boldsymbol{s}_{i i}\right)^{T}$,

$\mathbf{J}_{i} \mathbf{C}_{\mathrm{m}} \approx \mathbf{J}_{i} \mathbf{C}_{\mathrm{m} P}=\mathbf{J}_{i}(\mathbf{Z})(\mathbf{Z})^{T}=\mathbf{J}_{i} \sum_{i i=1}^{P}\left(\boldsymbol{\varsigma}_{i i}\right)\left(\boldsymbol{\varsigma}_{i i}\right)^{T}=\sum_{i i=1}^{P}\left(\mathbf{J}_{i} \boldsymbol{\varsigma}_{i i}\right)\left(\boldsymbol{\varsigma}_{i i}\right)^{T}$,

$\mathbf{J}_{i} \mathbf{C}_{\mathrm{m}} \mathbf{J}_{i}{ }^{T} \approx \mathbf{J}_{i} \mathbf{C}_{\mathrm{m} P} \mathbf{J}_{i}{ }^{T}=\sum_{i i=1}^{P}\left(\mathbf{J}_{i} \boldsymbol{s}_{i i}\right)\left(\mathbf{J}_{\mathrm{i}} \boldsymbol{s}_{i i}\right)^{T}$

$\mathbf{J}_{i} \boldsymbol{\varsigma}_{i i} \approx \frac{1}{\delta}\left[f\left(\mathbf{m}_{i}+\delta \boldsymbol{\varsigma}_{i i}\right)-f\left(\mathbf{m}_{i}\right)\right]$

Here, $\mathbf{C}_{m p}$ is a rank- $P$ approximation of the model parameter covariance matrix. The $C_{m p}$ and Jacobian matrix products required for the inversion (equation 5 ) are given by equations (7)-(8). $\mathbf{Z}$ is a $m \times p$ matrix and $\boldsymbol{\varsigma}_{i i}$ is the $i^{\text {th }}$ column vector of $\mathbf{Z}$. How to choose the finite difference interval $\delta$ is addressed by Lee and Kitandis (2014).

The diagonal entries of the posterior covariance matrix $\left(\mathbf{v}_{j j}\right)$ are often presented as the estimation of the variance and can be calculated without explicit construction of $\mathbf{v}$ (Lee and Kitanidis, 2014)

$\mathbf{v}_{\mathbf{j j}}=\mathbf{C}_{\mathrm{m} j j}-\left[\begin{array}{c}\left(\mathbf{J} \mathbf{C}_{\mathrm{m}}\right)_{j} \\ \mathbf{X}^{T}\end{array}\right]^{T}\left[\begin{array}{cc}\mathbf{J} \mathbf{C}_{\mathrm{m}} \mathbf{J}^{T}+\mathbf{C}_{\mathrm{d}} & \mathbf{J X} \mathbf{X} \\ (\mathbf{J X})^{T} & 0\end{array}\right]^{-1}\left[\begin{array}{c}\left(\mathbf{J} \mathbf{C}_{\mathrm{m}}\right)_{j} \\ \mathbf{X}_{j}^{T}\end{array}\right]$

where $\mathbf{C}_{\mathbf{m j j}}$ represents the $j^{\text {th }}$ diagonal entry of the model covariance matrix and $(\mathbf{J X})_{j}$ is the $j^{\text {th }}$ column of the product JX. In this work, Levenberg-Marquardt algorithm (by introducing a multiplier to the error matrix for dampening) is used to reduce the distance between simulation and observation.

Once the model parameters are determined, it is desirable to perform a resolution analysis by obtaining the resolution matrix $(\mathbf{R})$, which can be seen as a low pass filter that maps the true model 
parameters to the estimated model parameters (e.g., Alumbaugh and Newman, 2000). Each model parameter during the inversion is estimated from the averaging of other model parameters adjacent to the one of interest. The components of $\mathbf{R}$ can be interpreted as weights (each row in the resolution matrix) of the average of true model parameters for estimating each model parameter (Day-Lewis et al., 2005). The ideal resolution matrix would be an identity matrix that would imply that all model parameters are resolved perfectly. The deviation of the diagonal element from the identity matrix reveals the degree of averaging and smoothness. Thus, plotting diagonal elements of the resolution matrix in their corresponding blocks is indicative of the degree of smoothness. The diagonal elements of the resolution matrix (equation 11) inform the extent to which each estimated parameter is resolved independently.

The resolution matrix ( $\mathbf{R})$ is obtained by equation (12), which requires recovering the Jacobian matrix $\left(\mathbf{J}_{\mathrm{r}}\right)$ from the previously calculated product (equation 7 ) and inverse of low rank-approximation of the covariance matrix $\left(\mathbf{C}_{\mathrm{m} P}\right)$ as shown in equation (13);

$\mathbf{m}^{\text {estimate }}=\mathbf{R m}^{\text {true }}$,

$\mathbf{R}=\left(\mathbf{J}_{\mathrm{r}}^{T}\left(\mathbf{C}_{\mathrm{d}}\right)^{-1} \mathbf{J}_{\mathrm{r}}\right)^{-1}\left(\mathbf{J}_{\mathrm{r}}^{T}\left(\mathbf{C}_{\mathrm{d}}\right)^{-1} \mathbf{J}_{\mathrm{r}}\right)$

$\mathbf{J}_{\mathrm{r}}=\left(\sum_{\mathrm{ii}=1}^{P}\left(\mathbf{J}_{i} \boldsymbol{\varsigma}_{i i}\right)\left(\boldsymbol{\varsigma}_{i i}\right)^{T}\right)\left(\sum_{i i=1}^{P}\left(\boldsymbol{\varsigma}_{i i}\right)\left(\boldsymbol{\varsigma}_{i i}\right)^{T}\right)^{-1}$

It should be noted that $\mathbf{J}_{\mathrm{r}}$ is the Jacobian matrix mapped from the PCA space to the grid cells, while $\mathbf{J}$ is the Jacobian matrix calculated directly for every principal component.

\subsection{Forward model}

The incompressible fluid flow module of MRST (Lie, 2019) was used to simulate steady-state groundwater flow. It is used to calculate head and flux values at different points across a confined aquifer. Starting from the mass conservation law on a control volume, introducing the Darcy law, assuming incompressible fluid flow and steady-state condition, the final form of the equation reads:

$-\nabla \cdot[K(\mathbf{w}) \cdot \nabla h(\mathbf{w})]=\mathbf{q}(\mathbf{w})$

subjected to the following constant head boundary conditions across external boundaries:

$h=h_{\mathrm{D}}$ for $\overrightarrow{\mathbf{w}} \in \Gamma_{\mathrm{a}}$

Here, $\mathbf{w}=(x, y, z), K(\mathrm{~L} / \mathrm{T}), h(\mathrm{~L})$ and $\mathbf{q}[\mathrm{L} / \mathrm{T}]$ represent the hydraulic conductivity, head and fluid source or sink (inflow or outflow of fluid per volume at certain locations), respectively. $\Gamma_{\mathrm{a}}$ represents Dirichlet boundaries. The above equations are solved numerically to calculate the head values at grid points across the aquifer. The MRST uses the two-point flux approximation scheme $($ Lie, 2019$)$ to calculate the Darcy flux in each grid block. Starting from mass conservation, introducing the Darcy equation to the flux exchange at the face of a cell with its neighboring cells and imposing continuity of fluxes across all faces of a cell, the flux in each face (for instance in the x-direction) is calculated by: 
$\left[\frac{\Delta \mathrm{x}_{\text {cell }}}{\mathrm{K}_{\text {cell }}}+\frac{\Delta \mathrm{x}_{\text {neighbour }}}{\mathrm{K}_{\text {neighbour }}}\right]^{-1}\left(\mathrm{~h}_{\text {cell }}-\mathrm{h}_{\text {neighbour }}\right)=\mathrm{v}_{\text {face }}$,

Here, $\Delta x(L)$ is the length of the grid and $v_{\text {face }}(L / T)$ is the fluid flux. This equation is solved for all other faces to obtain the flux in all faces. The value of the flux attributed to each cell is the Euclidean norm of flux in all faces.

\section{NUMERICAL EXPERIMENTS}

\subsection{Setup of the synthetic test case}

To assess the information content of hydraulic head and groundwater flux data for the reconstruction of heterogeneous aquifers, a stationary multi-Gaussian log-hydraulic conductivity field (with constant storativity) is generated using the fast circulant embedding technique, resulting in the field, shown in Figure 2. In this study, we consider steady-state hydraulic tomography in which storativity does not play a role in simulated head or flux data and can be considered as a constant value. The generated aquifer is $550 \mathrm{~m}$ in length, $550 \mathrm{~m}$ in width and $5 \mathrm{~m}$ in depth. The aquifer is discretized into $110 \times 110 \times 1$ in $x-, y-, z$ - directions and corresponding block sizes are $5 \mathrm{~m} \times 5 \mathrm{~m} \times 5 \mathrm{~m}$, respectively. The aquifer is assumed to have one layer, and the log-hydraulic conductivity field has a multi-Gaussian distribution. The area of interest is chosen in the middle of the aquifer, away from the boundaries to reduce the boundaries' effect on the inversion. All boundaries are set to a constant head equal to 350 $\mathrm{m}$.

The correlation length used for generating the $Y$-field is $75 \mathrm{~m}$ and $45 \mathrm{~m}$ for $x$-and $y$-directions, respectively. The same field (same heterogeneity structure) with different variances of $0.5,1,2$, and 4 are generated to assess the effect of variance and number of observations on the inversion results. The mean $Y_{\text {mean }}$ is -3.57 for all cases, but the $Y$-fields variance and ranges are different for different experiments. This range of hydraulic conductivity is chosen to have measurable and realistic groundwater flux and head responses (both in real and synthetic aquifers).

We use a five-spot setup with a central borehole (P1) and four boreholes (P2, P3, P4 and P5) on the corners of the area of interest (bounded by white dashed lines in Figure 2). Other monitoring points are also considered between the boreholes, as shown by asterisk symbols. The aquifer is subjected to a series of pumping experiments in each borehole. The five boreholes are pumped sequentially (one at each time) and head/flux data are acquired in other boreholes and observation points. Two different boundary conditions in the borehole, namely, constant rate and constant head, are considered. When simulating pumping in one borehole, the head and flux values are recorded in other boreholes and monitoring points. The acquired flux and head data are noise-contaminated before being used to estimate the $Y$-field. 


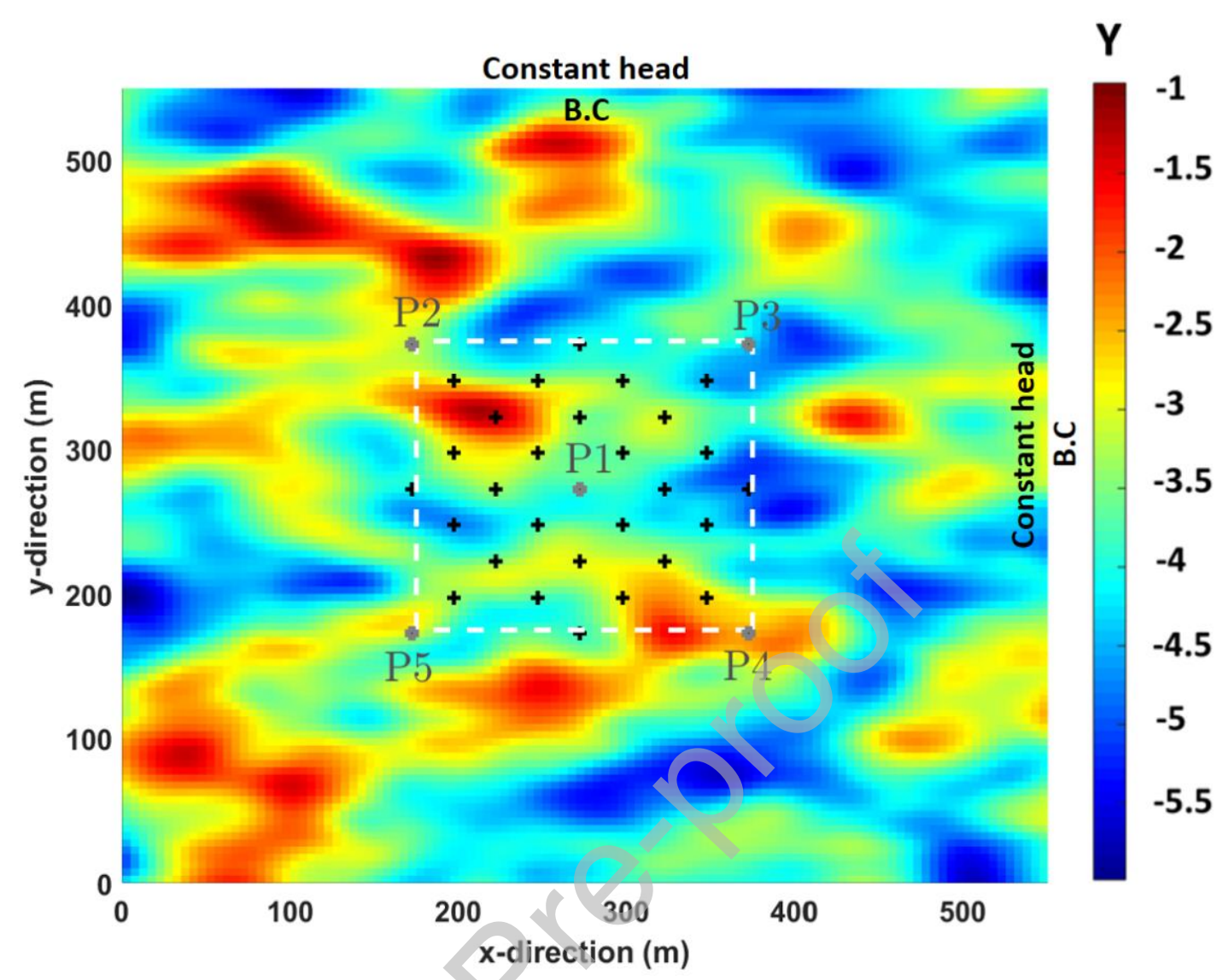

Figure 2: Reference Y-field (variance 4), borehole (P1 to P5), and monitoring locations (asterisks). All boundaries are set to the constant head. The white dash-lines crossing the side boreholes define the area of interest.

\subsection{Hydraulic tomography using head and flux data}

Our numerical inversion experiments aim to compare the relative merits of each data type and analyze how borehole boundary conditions (constant head or constant rate), the variance of the $Y$-field, and the number of observations affect the inversion results. The observational data are generated using the reference hydraulic conductivity field, and a normally distributed and independent error is added to the observations. The standard deviations of these errors are different in all cases. The errors' standard deviations were chosen to be in a realistic range while ensuring the same initial signal-to-noise ratio of 38 for all cases defined by running the code using $Y_{\text {mean }}$. The resulting measurement errors range from 0.05 to $0.013(\mathrm{~m})$ for the head and 0.055 to $0.01(\mathrm{~m} /$ day) for the flux. The relation between values of groundwater flux and measurement uncertainty is provided by Simon et al. (2021). This relation was used to define a reasonable range of the noise model. It should be noted that the uncertainty depends highly on the range of flux measurements and the duration of the active-DTS experiments. Typically, for a relatively large range of values, the accuracy is very good, but for very high or very low flows values, 
uncertainty is much greater (Simon et al., 2021). In this work, we assume that data quality in terms of signal-to-noise-ratio is the same for both head and flux data.

PCGA with previously mentioned geostatistical parameters (variance and correlation length) are used for the inversion. Increasing in the dimension of the problem results in massive computational needs. Considering the available computational methods, one may use the full covariance matrix, but if it is not possible, a sufficient number of components must be chosen to ensure that most of the heterogeneity features are captured. The truncation order ( $p$-rank) of the prior covariance matrix is chosen as 400 out of 12100 . Based on the recommendation by Lee et al. (2016), the truncation order $(P)$, which results in the relative Eigenvalue error below 0.01 would be sufficient to capture most of the covariance matrix structure. The relative Eigenvalue error is defined as the ratio of first to $(P+1)$ th Eigenvalue. We have chosen $P$ more conservatively. For the $Y$-field with variance 4 , the first Eigenvalue is 1411.47, while the 401st Eigenvalue is 0.047 giving the ratio of $3.25 \times 10^{-5}$.

The inversion starts with a constant value of $Y_{\text {mean }}$ and continues until the root mean square error between observed and simulated measurement, normalized with the error standard deviation (weighted root mean square error), defined in equation 15 reaches a value close to one,

WRMSE $=\sqrt{\frac{\frac{1}{N} \sum_{1}^{N}\left(\mathbf{d}-f\left(\mathbf{m}^{\text {estimate }}\right)\right)^{2}}{\sigma^{2}}}$,

here $N$ is the number of observations and $\sigma$ is the absolute value of the error's standard deviation. If no convergence is obtained, the inversion ends after 10 iterations.

\subsubsection{Boundary condition at the pumping borehole}

The steady-state hydraulic tomography is simulated considering two different borehole boundary conditions: constant rate (the borehole is being pumped with constant flow rate) and constant head (the head in the borehole is kept constant). Note that the external boundary conditions do not change and are kept fixed. As an example, the pumping rates for the field case with variance 4 ( $Y$-field variance) are $2400,4000,1750,5000$, and $3800\left(\mathrm{~m}^{3} /\right.$ day) for P1, P2, P3, P4, and P5, respectively. The equivalent constant head borehole boundary conditions are 324, 340, 300, 329 and $336(\mathrm{~m})$ for P1, P2, P3, P4, and $\mathrm{P} 5$, respectively. The inversion is performed on the whole domain but results are shown for the area of interest.

\subsubsection{Variance of $\gamma$-field and number of observation points}

The effect of the $Y$-field $(Y=\log 10(K))$ variance is investigated by considering four different variances $(0.5,1,2$ and 4). Furthermore, a different number of observation points are used to assess their impact on the final inversion results. The observation points are distributed symmetrically in the aquifer. The minimum number of observation points considered is the number of boreholes (4 observation points) and the maximum are the boreholes and the observation points shown by asterisks in Figure 2 (32 observation points). We distinguish between the number of observations and the number of observation points. For head and flux data, the number of observation points and number of observations are the same. For joint inversion, the number of observations is twice the number of observation points. 


\subsection{Performance Metrics}

To evaluate each data type's performance in estimating $Y$, we use the Frobenius norm and scatter plots of estimated versus reference $Y$ for each case. The Frobenius norm for the vector of difference between the reference $Y$ and estimated $Y$ is:

Norm $^{\mathrm{Fr}}=\sqrt{\sum_{1}^{N}\left|\mathbf{Y}_{\text {reference }}-\mathbf{Y}_{\text {estimated }}\right|^{2}}$,

Furthermore, the correlation coefficient between reference $Y$ and estimated $Y$-values and their corresponding slope lines are calculated. We stress that the comparison is based on the log of the hydraulic conductivity values and not the hydraulic conductivity itself, thereby, avoiding emphasizing large hydraulic conductivity values.

\section{RESULTS}

\subsection{Inversion of head data}

First, the head data are individually inverted. The resuits are presented for 4 observation points (only the observations in the boreholes), 8, 16 and 32 observation points. For each case, two different borehole boundary conditions are considered: constant rate and constant head. Figure 3 shows the estimated $Y$-field with a variance of 4 , and Table 1 represents the performance metrics. 
(a)

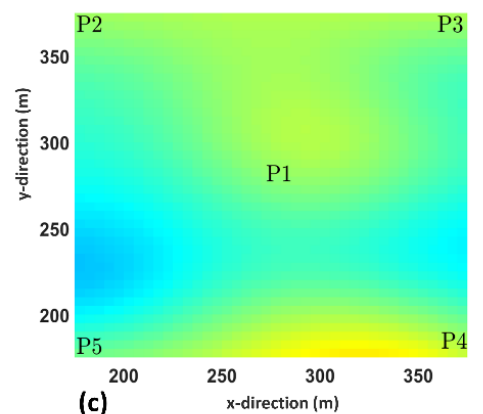

(c) $\quad{ }^{200} \quad 250 \quad 300$

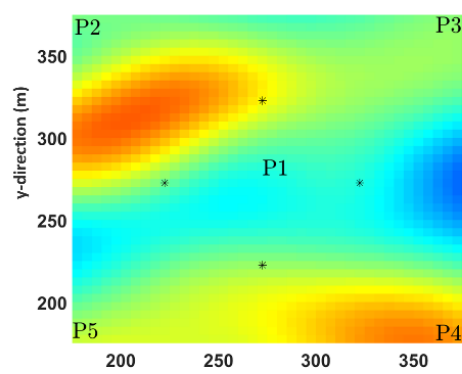

(e)

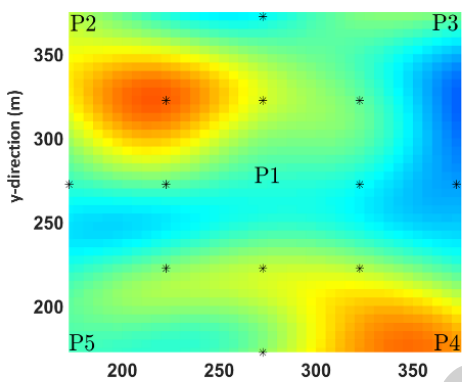

(g)

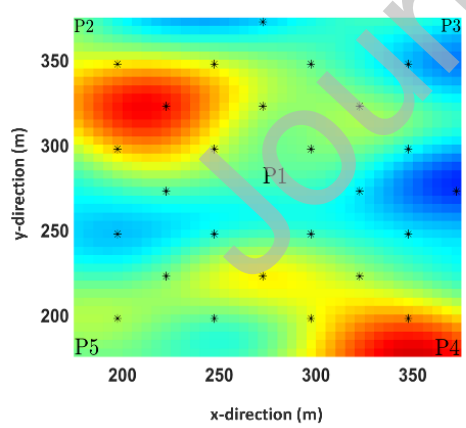

(b)

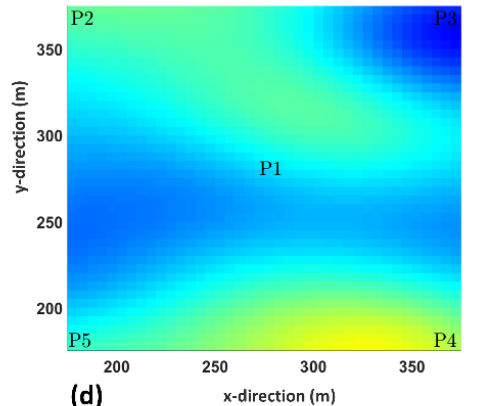

(d) $\quad 200 \quad 30$-direction (m)

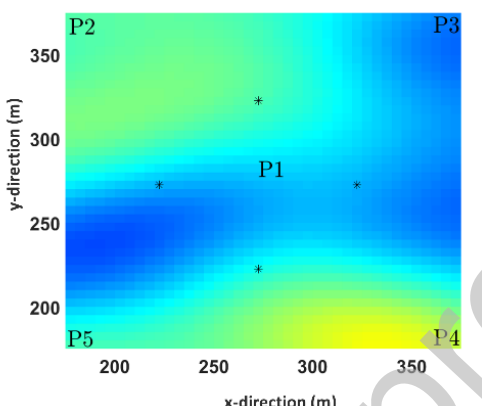

(f)

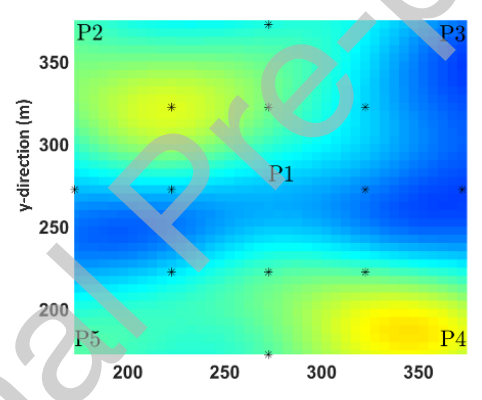

(h)

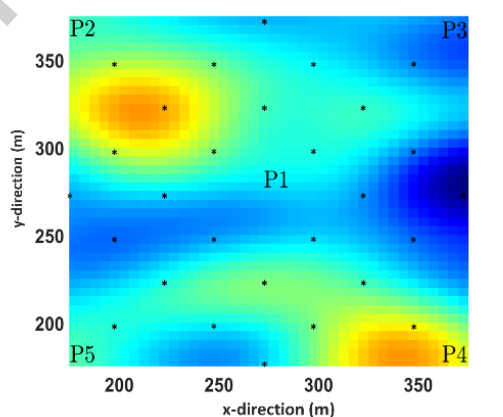

Figure 3: Hydraulic conductivity field (variance 4) estimates from hydraulic head data: (a) inversion result for 4 observations point and constant rate B.C., (b) inversion result for 4 observations point and constant head B.C., (c) inversion result for 8 observations point and constant rate B.C., (d) inversion result for 8 observations point and constant head B.C., (e) inversion result for 16 observations point and constant rate B.C., (f) inversion result for 16 observations point and constant head B.C., (g) inversion 
result for 32 observation points and constant rate B.C., (h) inversion result for 32 observation points and constant head B.C. (i) reference $Y$-field

Table 1: Performance metrics (in the area of interest) from the inversion of head data for the case of a $Y$ variance of 4.

\begin{tabular}{|c|c|c|c|c|c|c|}
\hline Variance & $\begin{array}{l}\text { Boundary } \\
\text { Condition }\end{array}$ & $\begin{array}{c}\text { Number of } \\
\text { observations }\end{array}$ & Frobenius norm & Correlation coefficient & Slope & $\begin{array}{c}\text { Final } \\
\text { WRMSE }\end{array}$ \\
\hline & & 4 & 68.4 & 0.27 & 0.13 & 1.19 \\
\hline & Constant & 8 & 48.27 & 0.75 & 0.62 & 1.05 \\
\hline & Rate & & & & & \\
\hline & & 16 & 30.4 & 0.9 & 0.76 & 0.97 \\
\hline \multirow[t]{5}{*}{4} & & 32 & 23.47 & 0.94 & 0.95 & 1.1 \\
\hline & & 4 & 85.5 & 0.49 & 0.32 & 1.00 \\
\hline & Constant & 8 & 75.15 & 0.68 & 0.48 & 0.96 \\
\hline & Head & 16 & 61.9 & 0.82 & 0.67 & 1.26 \\
\hline & & 32 & 54.90 & 0.9 & 0.93 & 1.23 \\
\hline
\end{tabular}

For all cases, we find that changing the borehole boundary condition from constant rate to constant head deteriorates the $Y$-field estimation. This is quantified by the fact that the Frobenius norm (Table 1 ) increases from 68.4 to $85.5,48.27$ to $75.15,30.4$ to 61.9 and 23.47 to 54.90 for $4,8,16$ and 32 observation points, respectively. Comparing Figures $3(\mathrm{a})$ to $3(\mathrm{~h})$ with the reference $Y$-field (Figure 3 (i)) also show that cases with constant rate boundary conditions is visually closer to the reference $Y$-field. The use of constant head borehole boundary condition results in an underestimation of $Y$-field values and the mean value of $Y$-field. For instance, in the case of 4 observation points, the mean value of the estimated $Y$-field is around - 4 for constant head boundary condition while it is -3.45 for constant rate boundary condition. The mean value of the reference $Y$-field is -3.57 . Adding more observations leads to better results in terms of how close the estimated $Y$-field is to the reference $Y$-field as judged by the Frobenius norm, the correlation coefficient and the slope of the 1:1 line when estimated $Y$-field is to the reference Y-field are plotted against each other. This is reflected in the improvement of the correlation coefficient from 0.27 to 0.94 for constant rate borehole boundary condition and from 0.49 to 0.93 for constant head boundary condition when adding observation points. Associated increases in the slopes from 0.13 to 0.95 and from 0.32 to 0.93 for constant rate and constant head boundary conditions further underline the previous statement.

As expected, the standard deviations of the posterior covariance matrix (Figure 4) decrease as the number of observations increase. We also see that for the cases involving 8 (Figure 4(c)) and 16 (Figure $4(\mathrm{e})$ observation points with constant rate $\mathrm{BC}$ have lower uncertainties than the corresponding number 

statement of proper BC for head data.

(a)

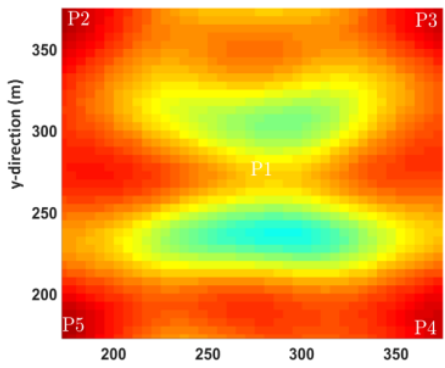

(c)

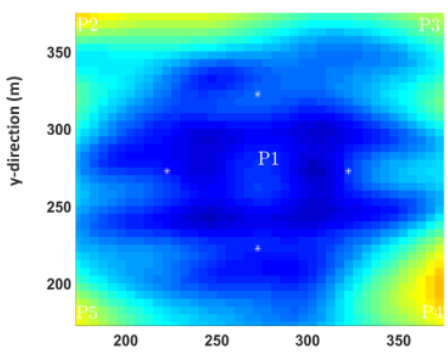

(e)

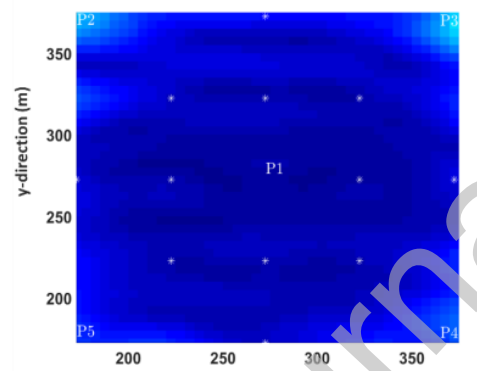

(g)

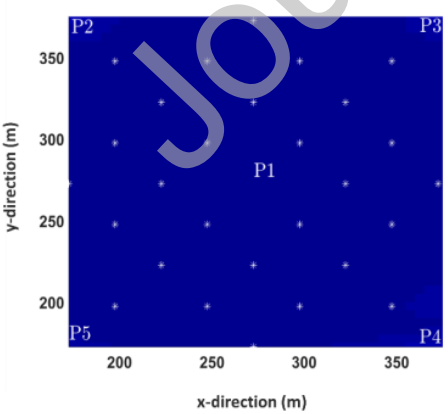

(b)

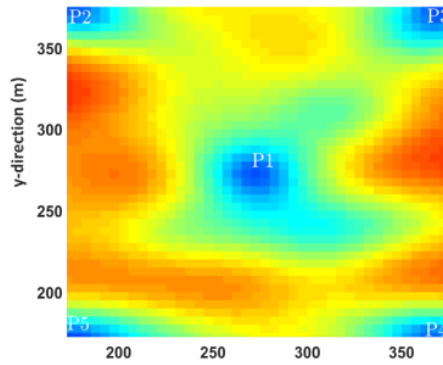

(d)

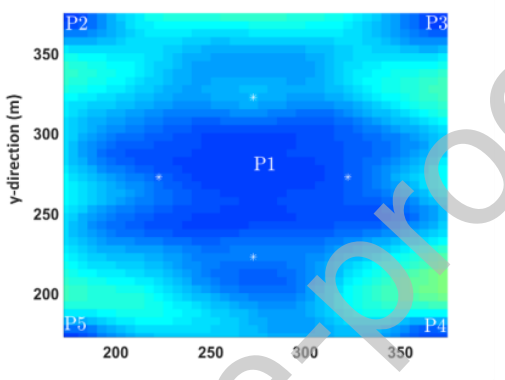

(f)

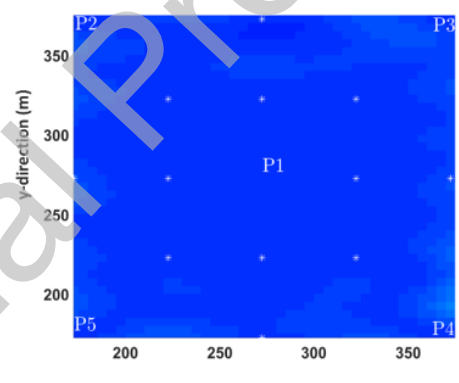

(h)

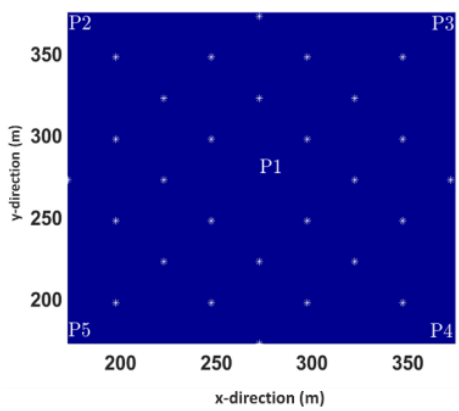

Figure 4: Posterior standard deviation of estimated Y-field (variance 4) using hydraulic head data: (a) for 4 observations point and constant rate B.C., (b) for 4 observations point and constant head B.C., (c) for 8 observations point and constant rate B.C., (d) for 8 observations point and constant head B.C., (e) for 16 
observations point and constant rate B.C., (f) for 16 observations point and constant head B.C., (g) for 32 observation points and constant rate B.C., (h) for 32 observation points and constant head B.C.

\subsection{Inversion of flux data}

We now consider the results obtained by individual inversions of flux data for a $Y$-field variance of 4 . Figure 5(a) to (h) show the $Y$-field estimates for 4, 8, 16 and 32 observation points subjected to constant rate and constant head borehole boundary conditions. Table 2 provides the corresponding performance metrics. 
(a)

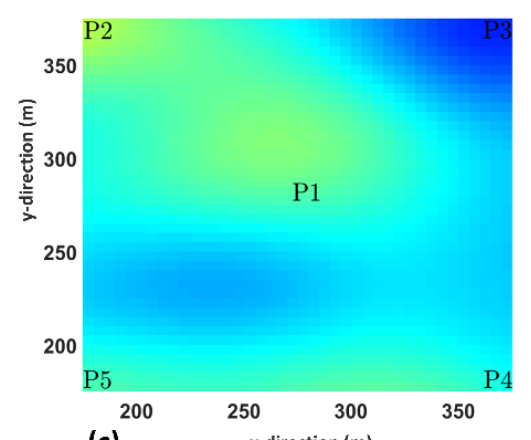

(c) $x$-direction (m)

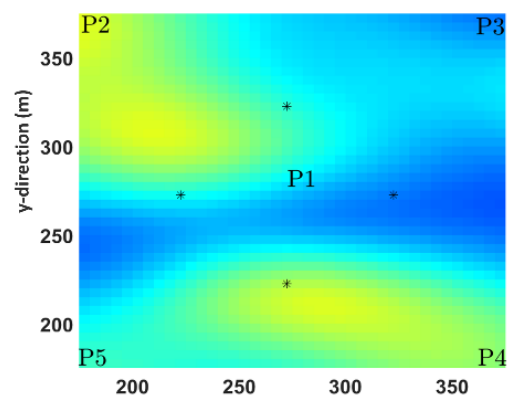

(e)

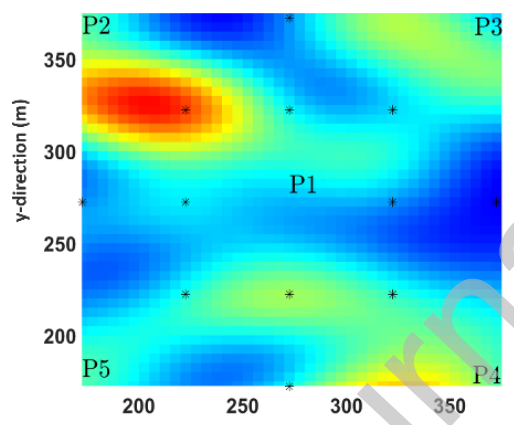

(g)

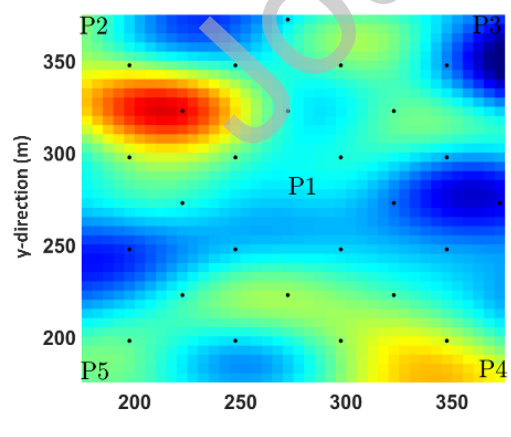

(b)

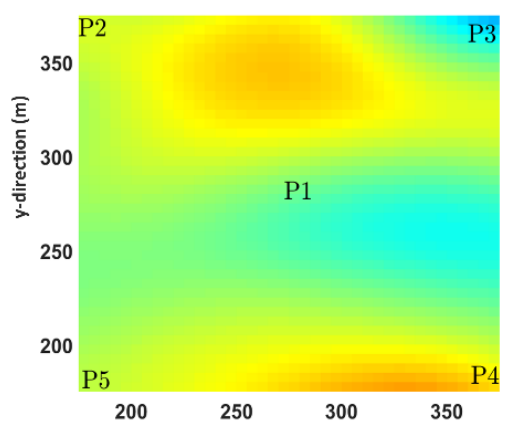

(d) ${ }^{200} \quad 250 \quad 300$

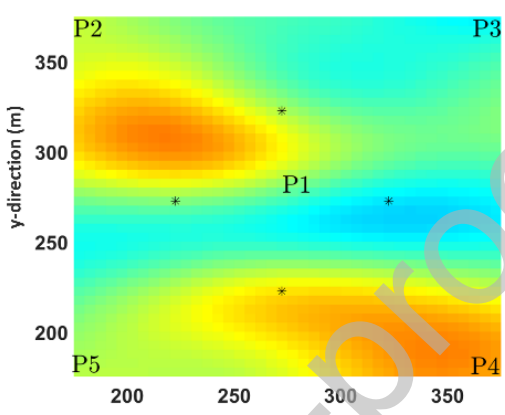

(f)

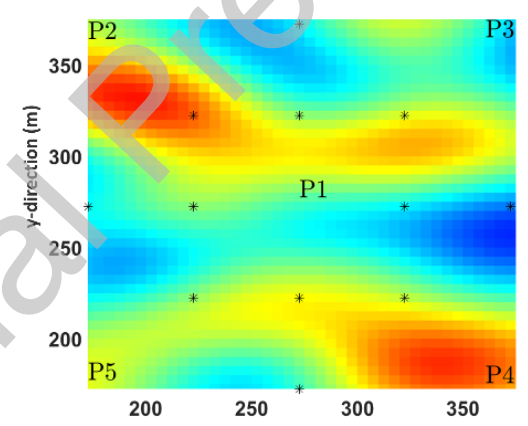

(h)

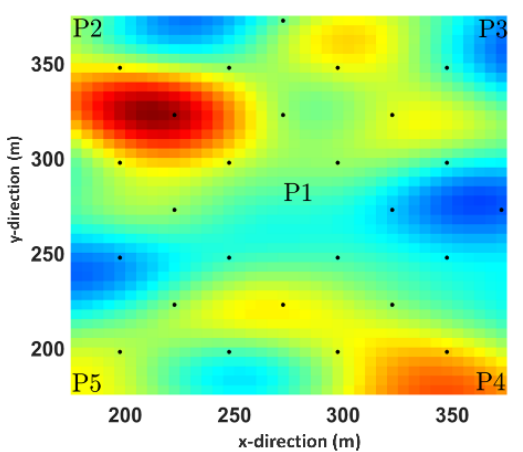

Figure 5: Hydraulic conductivity field (variance 4) estimates from flux data: (a) inversion result for 4 observations point and constant rate B.C., (b) inversion result for 4 observations point and constant head B.C., (c) inversion result for 8 observations point and constant rate B.C., (d) inversion result for 8 
observations point and constant head B.C., (e) inversion result for 16 observations point and constant rate B.C., (f) inversion result for 16 observations point and constant head B.C., (g) inversion result for 32 observation points and constant rate B.C., (h) inversion result for 32 observation points and constant head B.C., (i) reference $Y$-field

Table 2: Performance metrics (in the area of interest) from the inversion of flux data for the case of a $Y$ variance of 4.

\begin{tabular}{ccccccc}
\hline Variance & $\begin{array}{c}\text { Boundary } \\
\text { Condition }\end{array}$ & $\begin{array}{c}\text { Number of } \\
\text { observations }\end{array}$ & Frobenius norm & Correlation coefficient & Slope & $\begin{array}{c}\text { Final } \\
\text { WRMSE }\end{array}$ \\
\hline & 4 & 81.2 & 0.45 & 0.22 & 1.31 \\
$\begin{array}{c}\text { Constant } \\
\text { Rate }\end{array}$ & 8 & 65.61 & 0.76 & 0.56 & 0.77 & 1.19 \\
4 & 16 & 62.2 & 0.79 & 0.90 & 2.12 \\
4 & 32 & 53.6 & 0.9 & 0.29 & 1 \\
& 4 & 64.53 & 0.53 & 0.61 & 1 \\
Constant & 8 & 47.7 & 0.77 & 0.8 & 0.81 & 0.95 \\
Head & 16 & 44.72 & 0.92 & 0.91 & 1.45 \\
\hline
\end{tabular}

Contrary to head data, we find that constant head boundary conditions provide a better $Y$-field estimate when considering flux data. The better performance of the constant head (with respect to constant rate) boundary condition is seen, for instance, by comparing the values of the Frobenius norm given in Table 2. For the case of 4, 8, 16, and 32 observation points, the Frobenius norm decreases from 81.2 to $64.53,65.61$ to $47.7,62.2$ to 44.7 , and from 50.51 to 32.03 , respectively. Using constant rate boundary condition for the flux data results in an underestimation of the $Y$-field mean. Considering the case with 4 observation points, the estimated $Y$-field's mean value with the constant rate boundary condition is around -4 while it is around -3.4 for the constant head boundary condition.

Comparing the values of Frobenius norm for the head and flux data given in Table 1 and Table 2 reveals that for a small number of observations (4 observation points), using flux data with constant head boundary condition gives a better $Y$-field estimate compared to head data with constant rate boundary condition as the Frobenius norm decreases from 68.4 to 64.53 . This improvement is further supported by an increase in the correlation coefficient from 0.2744 to 0.446 and slope increase from 0.127 to 0.22 . For a larger number of observations, the performance of the two data types is similar when considering their ideal boundary conditions. It should be noted that inversion of head data using 32 observation points (constant rate $\mathrm{BC}$ ) results in an improved Y-field reconstruction when compared to inversion of the flux data with same number of observation (constant head $\mathrm{BC}$ ). Despite the notable difference in Frobenius norm for this case, we can see the values of correlation coefficient and slope of 
422 1:1 line is close to each other. Furthermore, final WRMSE for flux data is higher than head data (head 423 data are better converged than flux data) which may bring biasedness when comparing these two cases. 424 Finally, we do not observe the superiority of inversion of head data with 32 observation points (constant 425 rate $\mathrm{BC}$ ) compared to inversion of flux data with 32 observations points (constant head BC) for hydraulic conductivity field with lower variance.

The posterior standard deviation of the $Y$-field estimations is given in Figure 6 . Again, the estimation uncertainty decreases as the number of observations increase. Figure 6 (c) and (d) show the posterior estimation uncertainty for 8 number of flux data observations using constant rate and constant head $\mathrm{BCs}$, respectively. It can be seen that using constant head $\mathrm{BC}$ results in lower uncertainty than constant rate $B C$. Figures 6 (e) and 6 (f), which show posterior estimation uncertainty for 16 observation points of flux data, when constant rate and constant head BCs are used, respectively. It can be seen that using constant head BC for head data results in lower uncertainty of the estimated $Y$-field. This confirms our previous statement about the proper BC for inversion of the flux data. 
(a)

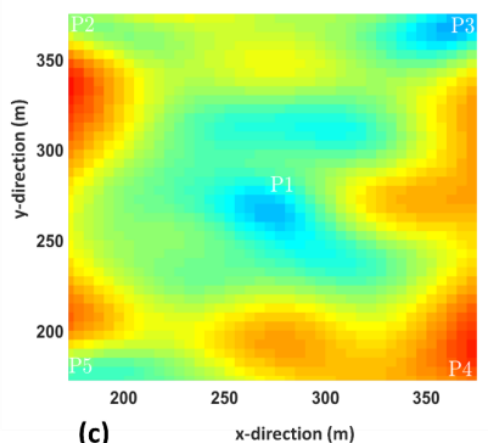

(c)

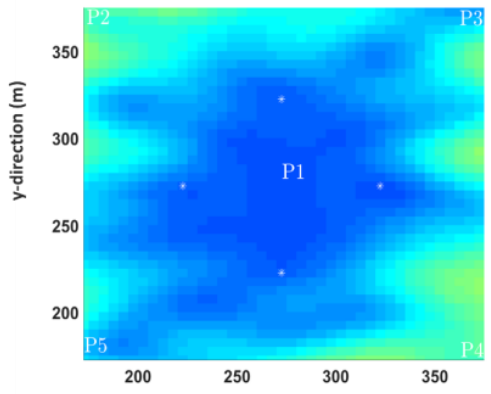

(e)

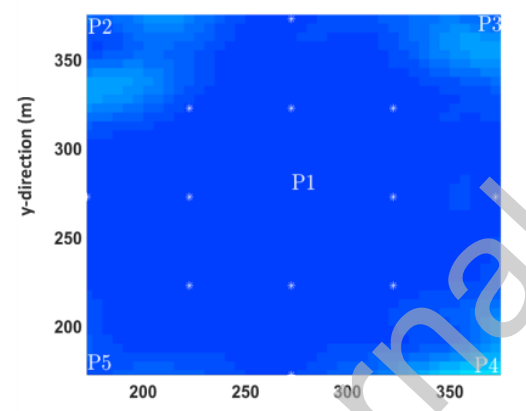

(g)

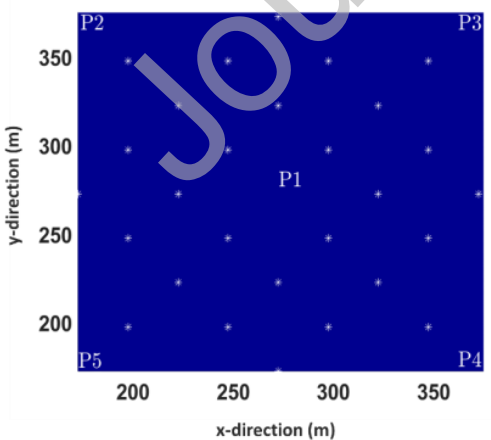

(b)

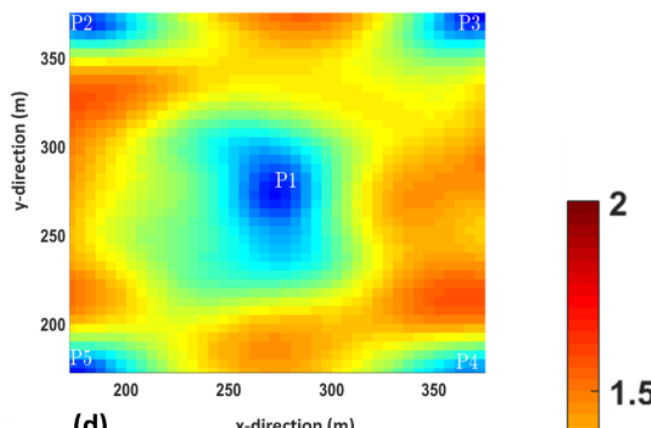

(d)
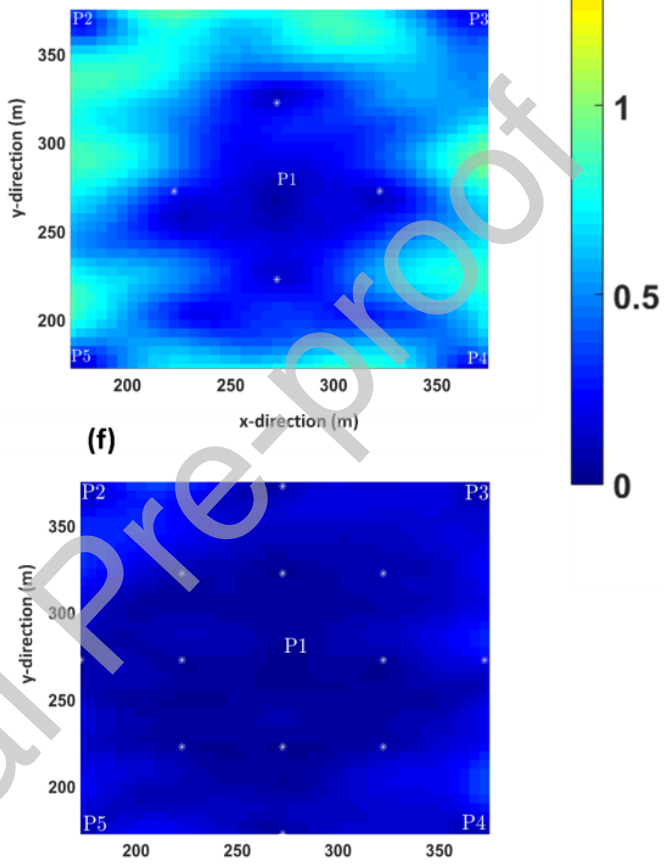

(h)

$x$-direction ( $m$ )

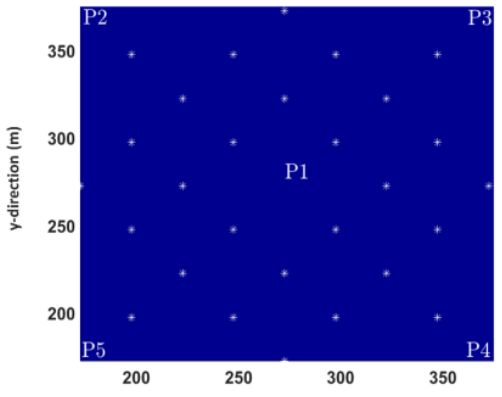

Figure 6: Posterior standard deviation of estimated Y-field (variance 4) using flux data: (a) for 4 observations point and constant rate B.C., (b) for 4 observations point and constant head B.C., (c) for 8 observations point and constant rate B.C., (d) for 8 observations point and constant head B.C., (e) for 16 
440 observations point and constant rate B.C., (f) for 16 observations point and constant head B.C., (g) for 32 441 observation points and constant rate B.C., (h) for 32 observation points and constant head B.C.

442

\subsection{Joint Inversion of flux and head data}

The results obtained by joint inversion of flux and head data are provided in Figure 7 (a) to (h) that show the $Y$-field estimate for $8,16,32$, and 64 observations subjected to the constant head and constant rate borehole boundary conditions. The inversion metrics are outlined in Table 3 . It should be noted that we have two measurements (head and flux) for each point shown leading to 64 observations for 32 observation points for instance. 
(a)

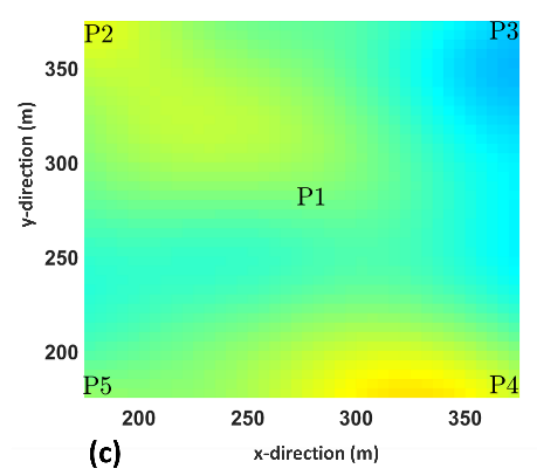

(c)

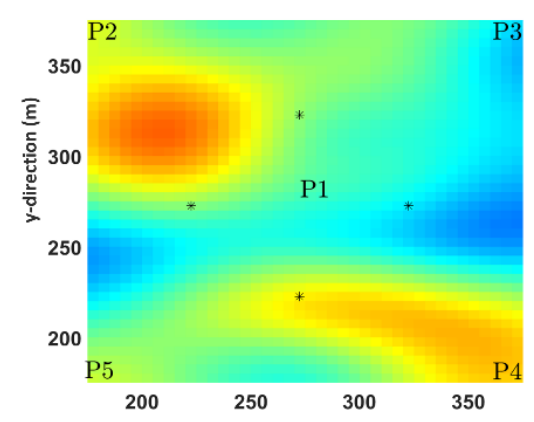

(e)

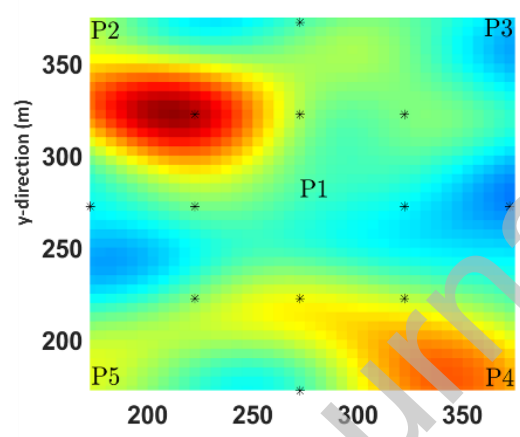

(g)

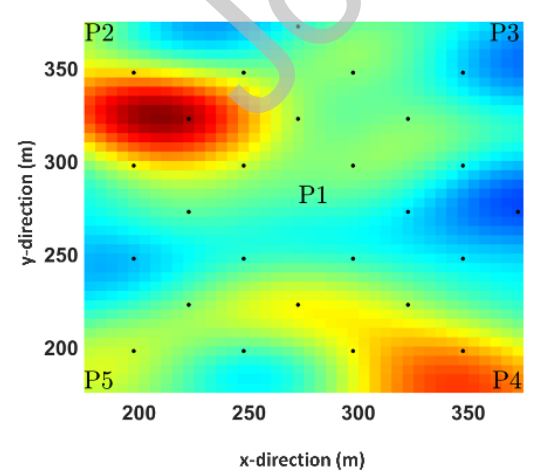

(b)

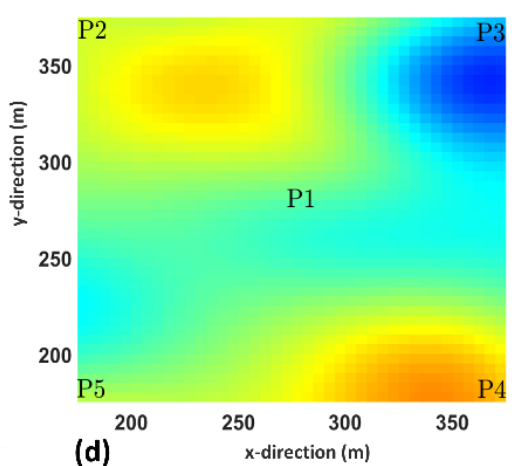

(d)

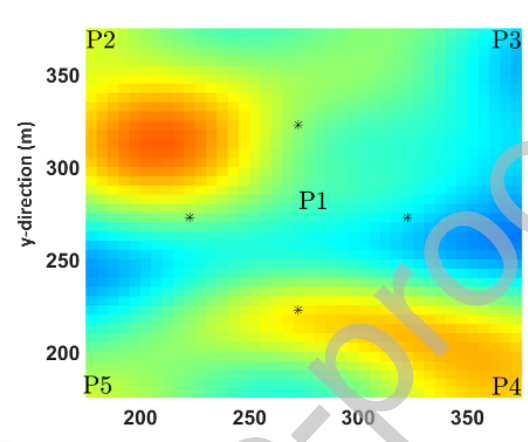

(f)

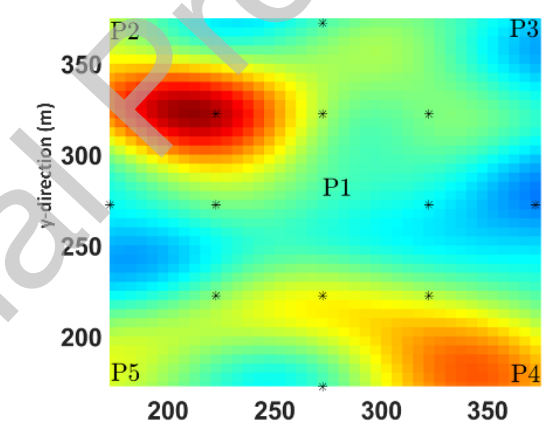

(h)

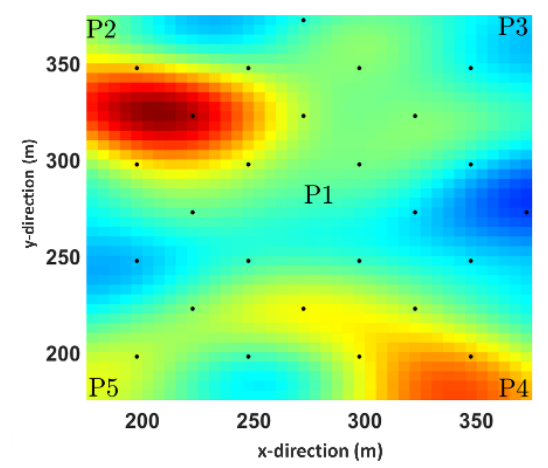

Figure 7: Hydraulic conductivity field (variance 4) estimates from joint inversion: (a) inversion result for 4 451 observations point and constant rate B.C., (b) inversion result for 4 observations point and constant 

$v^{2}$

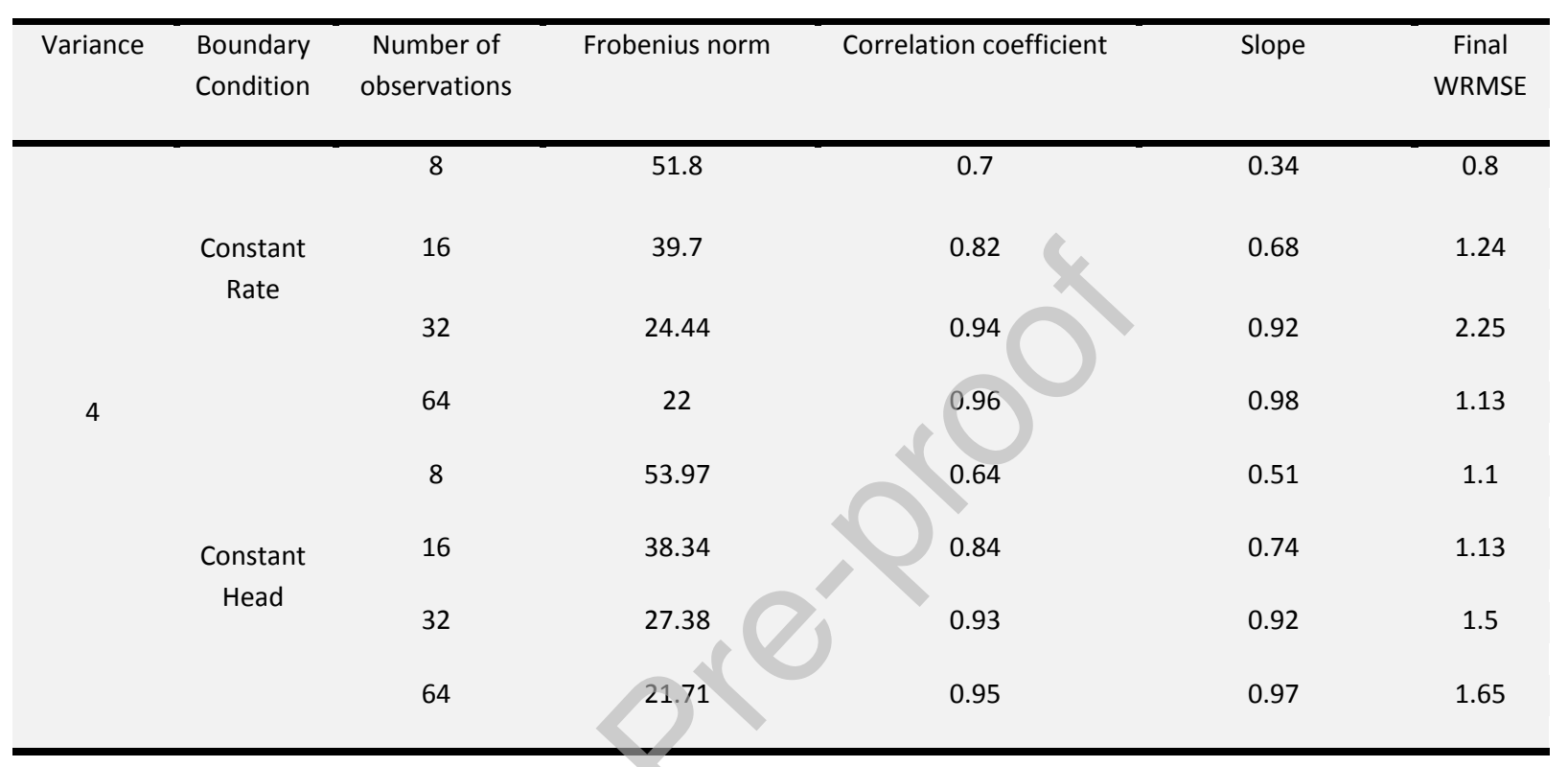

458

459

460

461

462

463

464

465

466

467

468

469

470

471

472

473

474

475

476

head B.C., (c) inversion result for 8 observations point and constant rate B.C., (d) inversion result for 8 observations point and constant head B.C., (e) inversion result for 16 observations point and constant rate B.C., (f) inversion result for 16 observations point and constant head B.C., (g) inversion result for 32 observation points and constant rate B.C., (h) inversion result for 32 observation points and constant head B.C., (i) reference $Y$-field

Table 3: Performance metrics for joint inversion of head and flux data in the area of interest

The Frobenius norms for 8, 16, 32 and 64 observations are 51.8, 39.7, 24.44 and 22, respectively, when considering constant head borehole boundary conditions, while they are 53.97, 38.34, 27.38 and 21.71 for constant rate boundary condition. For the same number of observations, the Frobenius norms are very similar regardless of borehole boundary conditions. In contrast to individual inversions, this suggests that they do not significantly affect the results obtained by joint inversion.

The joint inversion results (Table 3 ) do not demonstrate any significant improvement compared to the individual inversions (Tables 1 and 2) when considering the same number of observations. For 8 observations, the minimum Frobenius norm obtained for head, flux and joint inversion are 48.27, 47.7 and 51.8, respectively. For 16 observations, the minimum Frobenius norm obtained for head, flux and joint inversion are $30.4,44.72$ and 38.34 , respectively while it is $23.47,32.03$ and 24.44 for 32 observations. When considering the same number of observation points, the joint inversion has twice as many observations as the individual inversions. This leads to significantly better estimates of the hydraulic conductivity field.

Figure 8 shows the posterior estimation uncertainty of joint inversion of flux and head data for different number of observations and different type of BCs. Comparing the cases with same number of observations (different borehole BCs), we do not observe any notable difference in estimation uncertainty depending on BC. This is also consistent with our previous statement regarding the fact that borehole BCs play no significant role in joint inversion of head and flux data. 
477

(a)
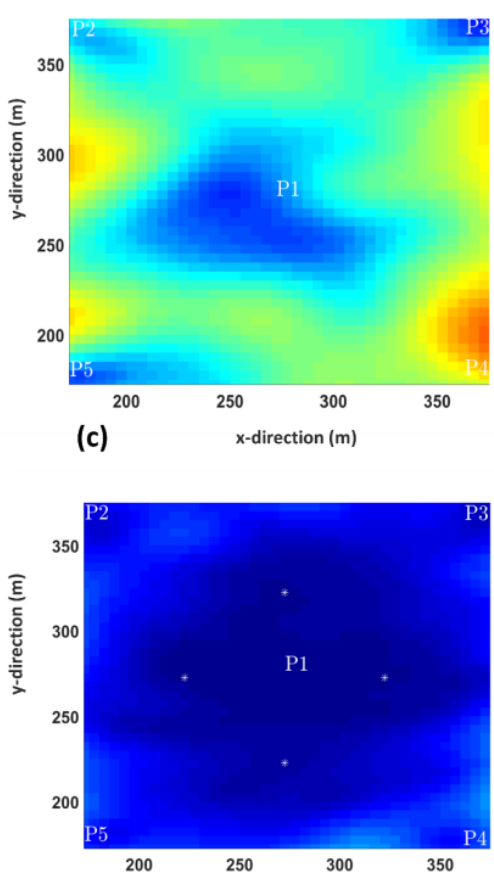

(e)

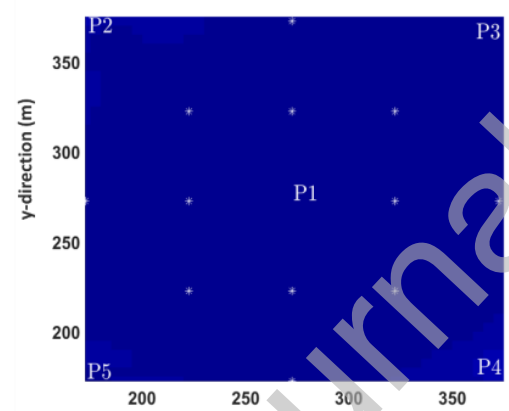

(g)

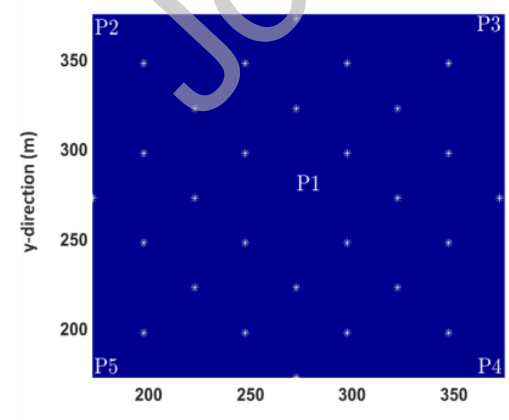

(b)

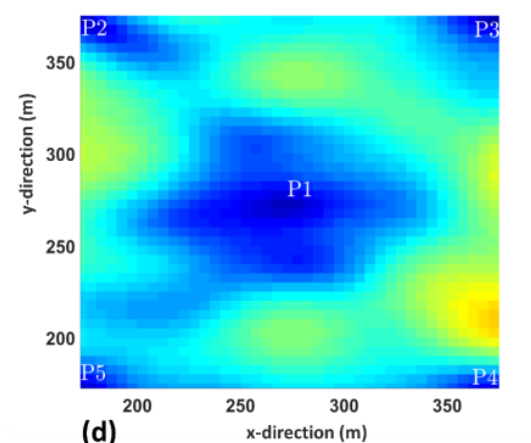

(d)

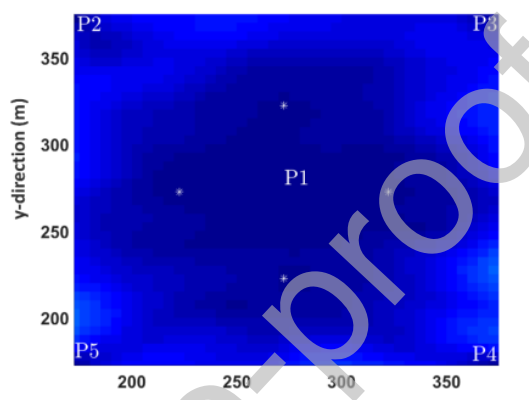

(f)

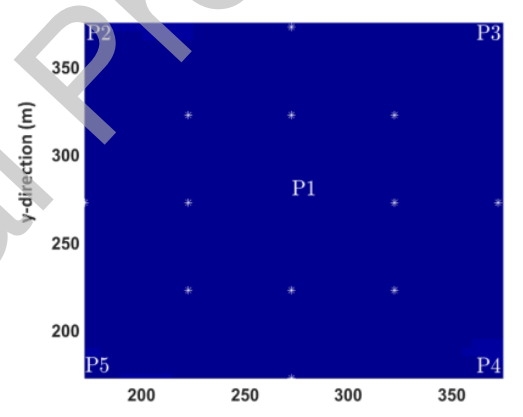

(h)

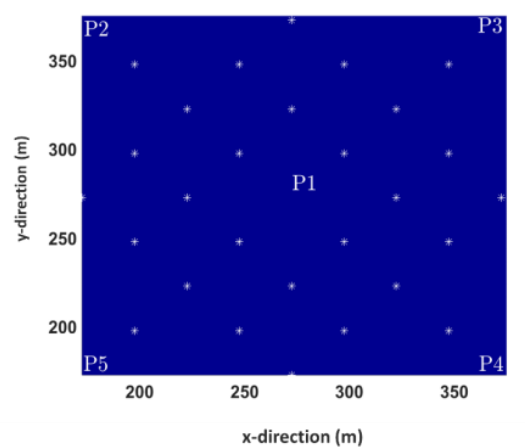

$\mathrm{x}$-direction (m)

Figure 8: Posterior Standard deviation of estimated Y-field (variance 4) using both head and flux data: (a) 
for 16 observations point and constant rate B.C., (f) for 16 observations point and constant head B.C., (g) for 32 observation points and constant rate B.C., (h) for 32 observation points and constant head B.C.

\section{DISCUSSION}

\subsection{General findings}

Considering the results of all 96 inversion scenarios considered, we find that inversion of flux data (with appropriate borehole boundary condition) leads to better resolved $Y$-field estimates than when considering head data particularly when a small number of observations are available. Furthermore, the quality of the inversion results is strongly dependent on the type of boundary condition used in the borehole. The performance metrics in Tables 1 and 2 suggest that it is more suitable to use constant rate borehole boundary condition for head data and constant head borehole boundary condition for the flux data as reflected in Frobenius norms' values. The reason is that if the observation is head data and the borehole boundary is set to constant head, the model response (head) will have less sensitivity to change of $Y$-field values. The same argument is also valid for the flux data. Once pumping with a constant rate, the value of groundwater flux is fixed, and the distribution of hydraulic gradient will be dependent on the distribution of the hydraulic conductivity. This means that measured groundwater flux would not be so sensitive to the distribution of hydraulic conductivity. When pumping with a constant head, the head gradient would be fixed, and the distribution of the groundwater flux will be highly dependent on the distribution of the hydraulic conductivity while the hydraulic gradient would not be very dependent on the distribution of the hydraulic conductivity. Even though no specific sensitivity analysis was performed but the explained behavior could be seen in the calculated Jacobian matrix values (the sensitivity of the forward model output at observation points with respect to the unknown model parameters) which were quite much smaller in case of inappropriate boundary conditions. The estimation uncertainty for head, flux and joint inversion of both data reveals the role of boundary condition in the reconstruction of the $Y$-field. Inversion of head data with constant rate BC results in lower uncertainty than using constant head BC. Inversion of the flux data using constant head $B C$ will be less uncertain than using constant rate $B C$. However, the estimation uncertainty for joint inversion of both data is almost the same for both type of BCs. Further studies, which consider transient hydraulic tomography and 3D porous media, would be very useful to confirm and investigate how quality of the inversion results depends on the type of boundary condition.

This may indeed have some consequences for field experiment where the effect of the borehole boundary is essential for proper experimental design. Our results suggest that the experimental designs should ensure that once head data are intended to be used for the inversion, wells must be pumped at a constant rate while for the inversion of the flux data, the head in the borehole should be kept fixed. Other borehole boundary conditions lead to an underestimation of hydraulic conductivity values. However, for the joint inversion of both data, the type of borehole boundary conditions does not play a significant role. 
Tso et al. (2016) and Zha et al. (2014) found that joint inversion of head and flux data results in better estimation of $Y$-fields in porous and fractured media compared to the head data. Here, we find that joint inversion does not offer any advantage over the individual inversion of the flux and head data when considering an equal number of observations and ideal borehole boundary conditions. However, measurements distributed across the aquifer could potentially reveal more information about the heterogeneity. Our results rather suggest that, for a constant signal-to-noise-ratio, the inversion performance depends largely on the number of observations. For a small number of observations, the flux data provides a superior $Y$-field estimate compared to inversion of head data, while for the higher number of observations, all data types perform similarly. However, if we would be able to measure flux and head data at the same location, then for the same number of observation points, joint inversion of flux and head data provide better estimates of $Y$-field as the number of observations are doubled. Furthermore, we demonstrated the importance of borehole boundary conditions for hydraulic tomography experimental design when performing individual inversions.

A resolution analysis for the case of the variance of 4 and 4 measurement points demonstrates that flux data can better resolve the hydraulic conductivity field compared to head data (Figure 9). Figure 9 shows the diagonal elements of the resolution matrix (calculated in the final inversion iteration) for head data, flux data, and joint inversion of both data are plotted on their corresponding blocks, respectively. Considering the best $Y$-field estimates obtained for the head (constant rate boundary condition) and flux (constant head boundary condition) data for calculating the resolution matrices, as shown in Figure 9 (a) and 9 (d), it can be stated that model parameters (hydraulic conductivity values) are better resolved by flux data. This is manifested by comparing both the values and coverage area of diagonal elements larger than 0.005. When head data are used for the inversion, the degree of smoothing and averaging is higher compared to the case in which the flux data are used. It is worth noting that, since PCGA does not calculate the full Jacobian matrix, it has the potential to blur the resolution matrix. However, we have chosen more PCA elements than recommended to ensure high fidelity realizations with respect to original geostatistical model 
(a)
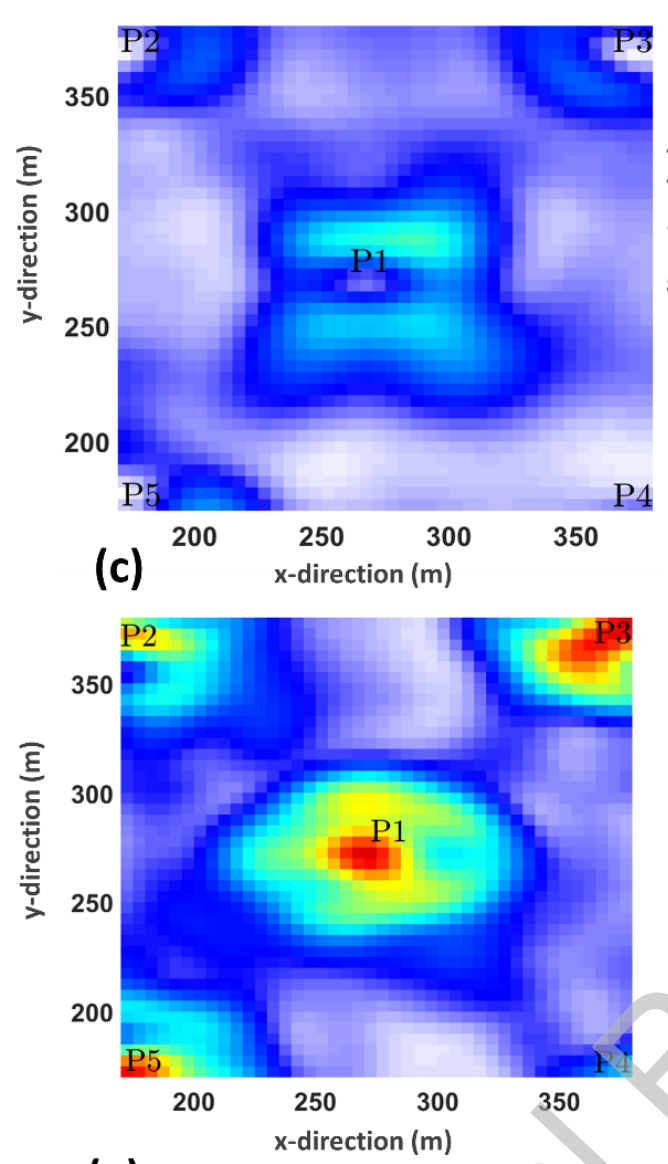

(e)

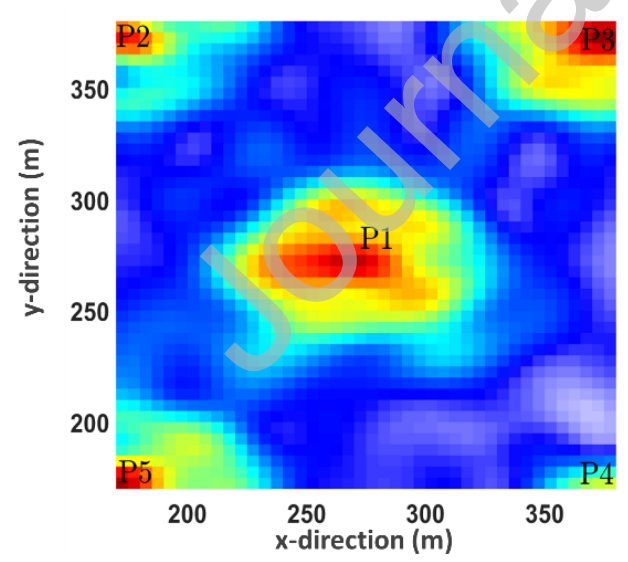

(b)
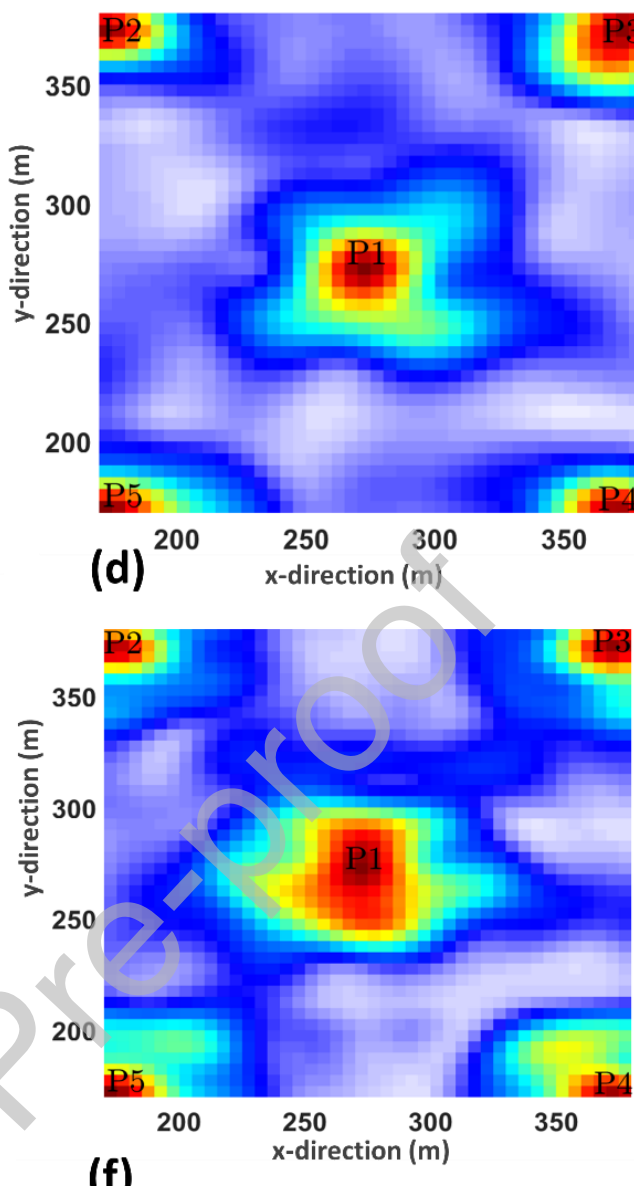

(f)

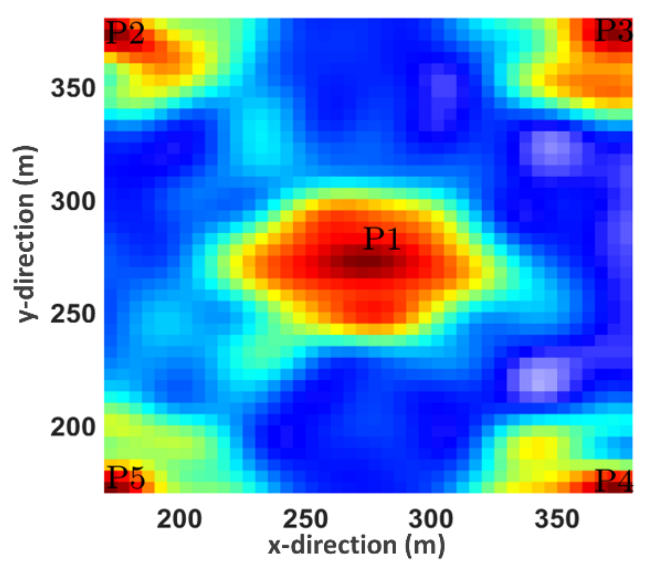

Figure 9: Diagonal element of the resolution matrix for (a) $Y$-field obtained by inversion of head data (4 observation points - borehole boundary is set to constant rate), (b) $Y$-field obtained by inversion of head data (4 observation points - borehole boundary is set to constant head), (c) $Y$-field obtained by inversion of flux data (4 observation points - borehole boundary is set to constant head), (d) $Y$-field obtained by inversion of flux data (4 observation points - borehole boundary is set to constant rate), (e) $Y$-field obtained by joint inversion of both data (4 observation points - borehole boundary is set to constant 
rate), (f) $Y$-field obtained by joint inversion of both data (4 observation points - borehole boundary is set to constant head).

\subsection{The effect of number of observations and variance}

Figures 10 (a) to (d) show the correlation coefficient (between estimated $Y$-field and reference $Y$ field) versus the number of observations for different type of data and borehole boundary conditions. It is seen that as the number of observations increases, the correlation coefficient also increases for all types of data and boundary conditions. For a small number of observations, flux data are superior to head data. The difference between the correlation coefficient of flux and head data is the strongest for a small number of observations, while the difference gradually decreases as the number of observations increases and at a high number of observations, they converge. This is a consequence of the decreasing distance between data points as the number of observations increases, thereby decreasing the radius of averaging. The gains by joint inversion for a prescribed number of observation points is that performance is independent of the borehole boundary condition and we need half as many boreholes if we are able to measure head and flux data at the same location.

The variance of the hydraulic conductivity field affects the final values of the correlation coefficient. The higher the variance, the lower the correlation coefficient (especially for a small number of observations), and also the more challenging it is to reach a WRMSE close to 1.

(a)

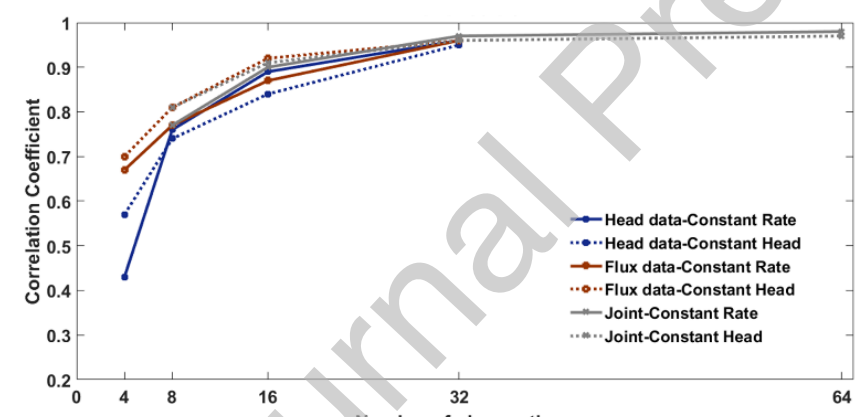

(c)

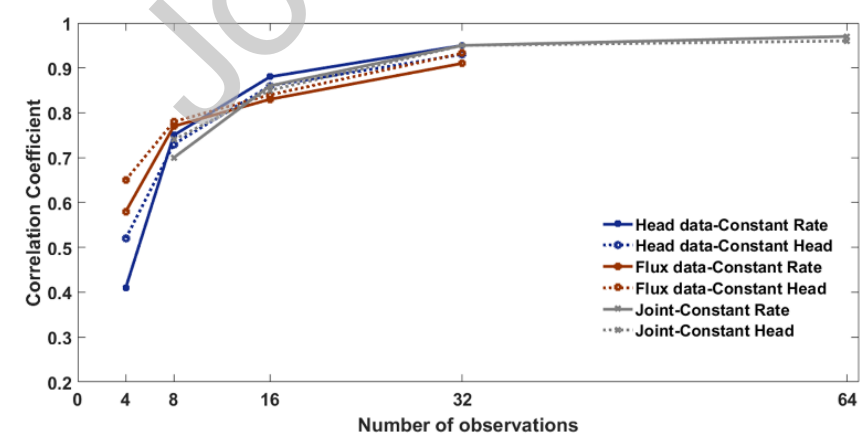

(b)

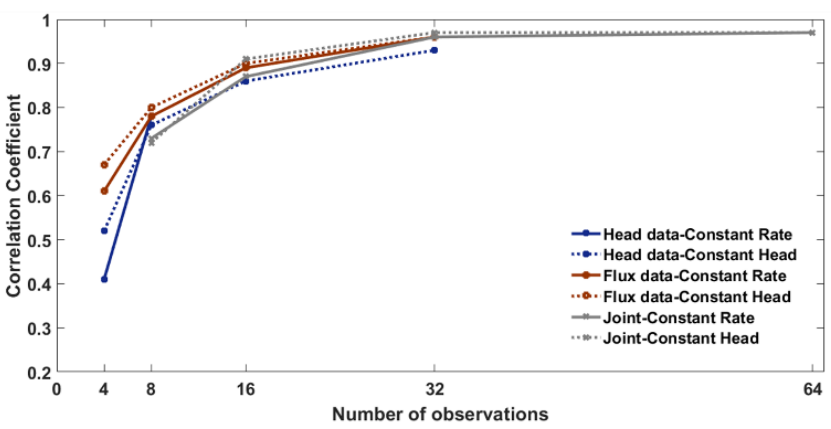

(d)

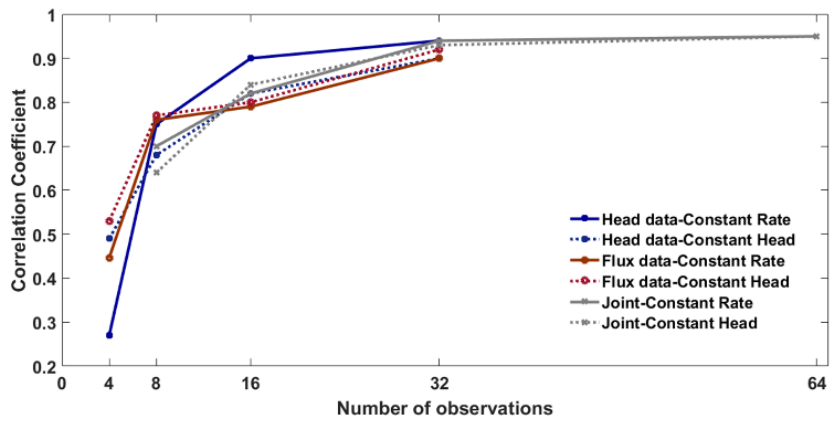

Figure 10: Correlation coefficient versus number of observations for reference hydraulic conductivity field with (a) variance $=0.5$, (b) variance $=1$ (c), variance $=2$ (d), variance $=4$. The Blue, red and gray color show the results for head data, flux data and joint inversion of both data, respectively. The data with 
577 constant rate borehole boundary condition is marked with solid line while the data with constant head

578 borehole boundary condition is shown by the dashed line.

579

580

581

582

583

584

585

586

587

588

589

590

591

592

593

594

595

596

597

598

599

\subsection{The effect of truncation order $(P)$ on final inversion results}

One of the inversion cases (variance of 4, 32 observation points, joint inversion of head and flux data) was chosen to investigate the effect of the truncation order $(P)$ on the final inversion result. Inversions were performed using truncation orders of $25,50,100,200,400,800$, and 1600 . The inversions were performed on a server with one Terabyte (1 Tb) memory, 4 processors (Intel Xeon CPU E7-4850 v4 @ $2.10 \mathrm{GHz}$ ) and 40 cores in parallel mode. Figure 11 shows the $Y$-field estimated for each $P$ value, the effect on the correlation coefficient, and elapsed time for each geostatistical iteration. For a truncation order of 25 , we capture an overly smooth version of the true model with a correlation coefficient of 0.84 . By setting the truncation order to 50,100 , and 200 , the correlation coefficient increases to $0.88,0.91$, and 0.94 , respectively. The truncation order of 400 (used in our study) with a correlation coefficient of 0.96 is the point beyond which increasing the truncation order does not significantly improve the correlation coefficient. So, the truncation order leads to improvement of $Y$ field reconstruction up to some points and after this point, it is only the computational time that increases as the inversion performance is data limited. The computational time increased exponentially for large $P$ values. The right choice of $P$ is critical to ensure sufficient reconstruction of the hydraulic conductivity field while keeping the computational time low. The truncation order should be chosen based on the degree of heterogeneity and the computational resource available. It would help perform inversion using different numbers of principal components to ensure the proper choice of the number of principal components. 
(a)

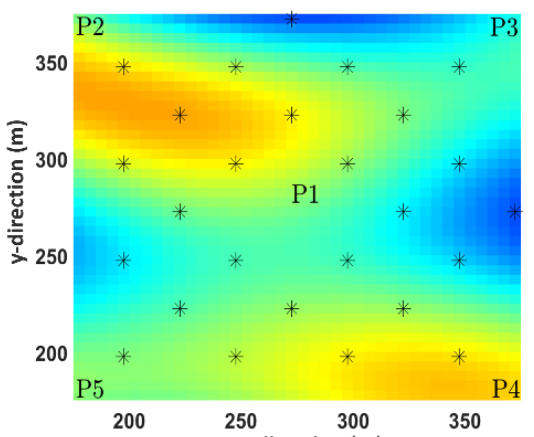

(d)
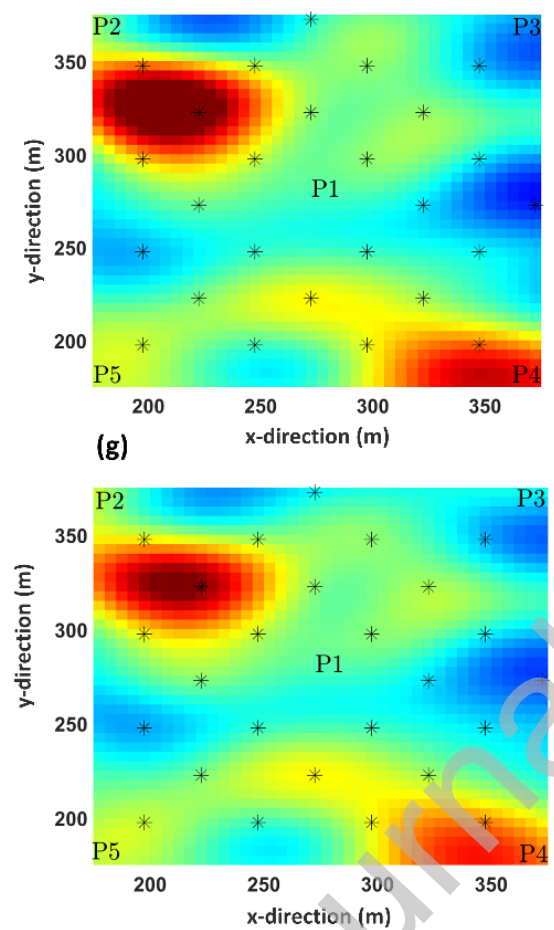

(b)

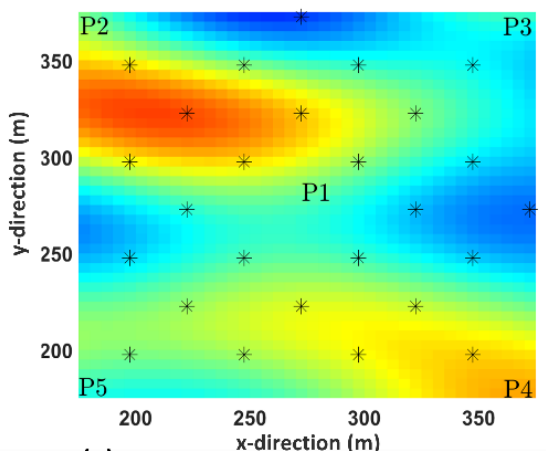

(e)

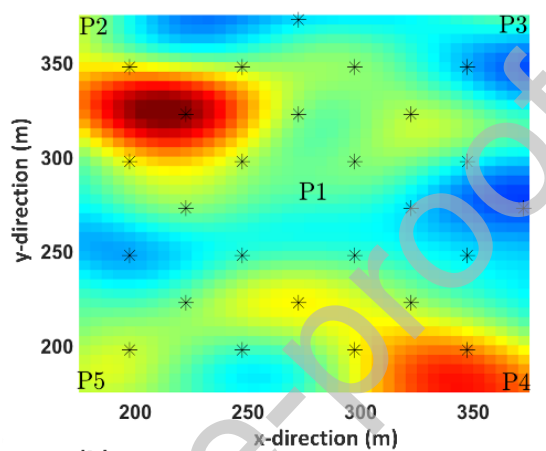

(h)

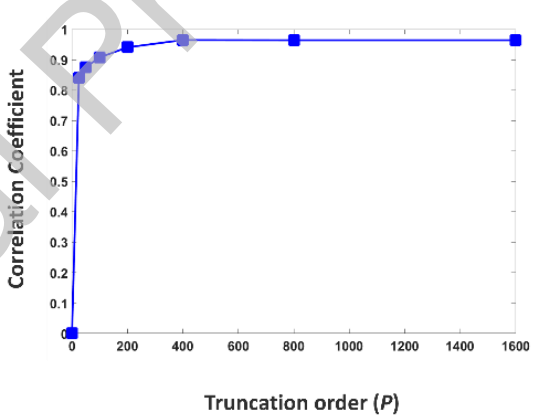

(c)
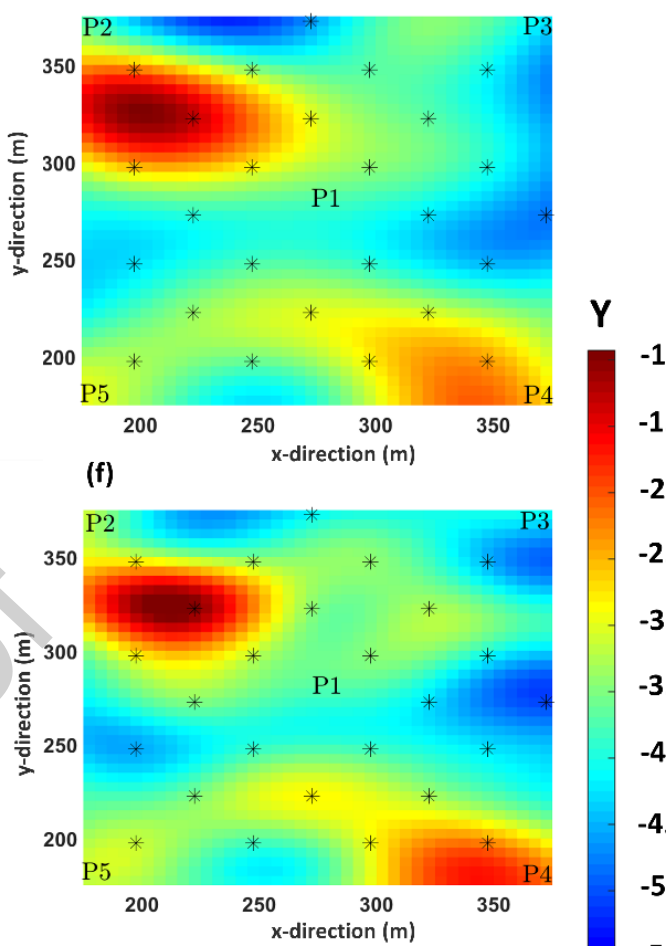

(i)

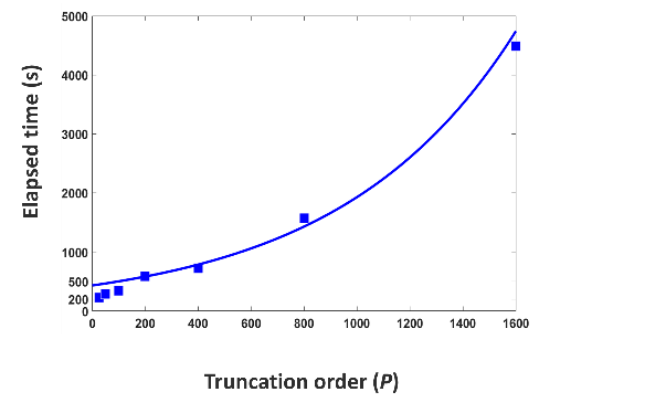

Figure 11: Estimated $\gamma$-field for truncation order of (a) 25, (b) 50, (c) 100, (d) 200, (e) 400, (f) 800, (g) 1600. (h) Correlation coefficient versus truncation order, (i) elapsed time per one iteration versus truncation order

\subsection{Implications for field implementations}

Our results highlight the added value of using the flux data individually or jointly with head data in hydraulic tomography to achieve an enhanced reconstruction of the hydraulic conductivity field compared to using head data alone. This improvement is particularly pronounced when considering a small number of observations, a more likely setting for field applications. However, using only flux data requires setting the borehole boundary condition to constant head, which is feasible (using pumps whose rates are controlled with water level) but would be more challenging than pumping at a constant 
612

613

614

615

616

617

618

619

620

621

622

623

624

625

626

627

628

629

630

631

632

633

634

635

rate during the field experiments. However, measuring the flux data during pumping (with constant rate) and joint inversion of both data would be quite feasible and removes the limitation of the borehole boundary condition. Additional simulations (not shown) revealed that adding even one relevant observation (head data once pumping with constant rate and flux data once pumping with constant head) allowed for proper estimation of the hydraulic conductivity. Moreover, if one could measure the head and flux data at the same location, by doubling the number of observations, the $Y$-field estimate would be significantly improved. The potential application of FO cables for pressure measurement is discussed by Butler et al. (1999) and a recent application for drawdown measurements during pumping tests is demonstrated by Tiedeman and Barrash (2020). A proper setting for the collection of head and flux data could include head measurements at boreholes while taking flux measurements at other locations using the FO-DTS technique. It is also worth noting that groundwater flux measurement is not as easy as measuring the head since it requires much more equipment than a simple pressure sensor. It is also true that one can measure the water level in all environments while groundwater flux measurement is currently possible for granular, unconsolidated aquifers (Simon et al., 2021). On the other hand, FO-DTS measurements may provide groundwater flux data at a high spatial resolution (Simon et al., 2020).

The results presented in this paper are only valid for steady-state hydraulic tomography. The method for measuring ground water flux from active FO-DTS experiments estimates has been developed works in steady-state hydraulic conditions (des Tombes et al., 2019; Simon et al., 2021, del Val et al, 2021), so we used steady state also for head data. Transient hydraulic tomography would probably result in better reconstruction of hydraulic conductivity field estimation. Transient hydraulic tomography provides the opportunity to resolve the storage, thanks to the numerous transient data available. The best practice would be to use all available information (transient hydraulic head data) and use groundwater flux data as additional constraint.

\section{CONCLUSIONS}

We used a numerical model representing a one-layer heterogeneous aquifer along with a geostatistical inversion approach (PCGA) to assess the information content of head and flux data. We varied the observation type, the number of observation points, the hydraulic conductivity variance (with the same field structure) and the borehole boundary conditions. For a small number of observation points, we find that flux data produced a better $Y$-field compared to head data. When increasing the number of observation points and using appropriate borehole boundary conditions, the effect of the data type vanishes, and all converge to the same results as the sampling distance between points becomes smaller. For the same number of observation points, if we are able to measure the head and flux data at the same location, joint inversion of head and flux data provides an improved estimate compared to the individual inversion of head or flux data due to the doubling of the number of observations. This means that the head and flux data measured at the same location provide complementary information. The type of borehole boundary conditions used in the tomography and modeling affects the inversion results. The appropriate boundary condition for head and flux data is constant rate and constant head, respectively, while joint inversion performance is independent of the 
boundary type. Inappropriate selection of borehole boundary conditions may result in an underestimation of the $Y$-field values which is also reflected in posterior estimation uncertainties. Comparing the estimation uncertainty, it can be seen that using head and flux data with inappropriate borehole $\mathrm{BC}$ results in higher uncertainty compared to the case when proper borehole BCs are used. Measuring flux data during a hydraulic tomography experiment is now feasible, especially for shallow sandy aquifers where active Distributed Temperature Sensing, can be deployed using direct push method to install the fiber optic cables into the sediments. Since the inversion is particularly sensitive to the number of measurements, groundwater flux measurements by active DTS can be particularly useful since it may provide a large number of measurements thanks to the high spatial resolution of fiber optic temperature measurements. Moreover, it can be also particularly useful in aquifers where the head drop due to the pumping is small, but there may be high groundwater fluxes. This should lead to interesting developments of hydraulic tomography experiments in the near future.

\section{ACKNOWLEDGMENTS}

ENIGMA ITN project that has received funding from the European Union's Horizon 2020 research and innovation programme under the Marie Sklodowska-Curie Grant Agreement No 722028. In our work we relied on the PCGA implementation in Python (pyPCGA) by Lee et al. (2016) available on GitHub (https://github.com/jonghyunharrylee/pyPCGA/). We would like to appreciate SINTEF for providing free access to the Matlab Reservoir Simulator Tool (MRST) which is available on the SINTEF website (https://www.sintef.no/projectweb/mrst/). We would like to thank Dr. Ty Ferre and two anonymous reviewers for the comments that greatly helped us improve the manuscript.

\section{CRediT authorship statement}

Behzad Pouladi: Writing - original draft, Writing - review \& editing, Methodology, Conceptualization, Software, Formal analysis, Investigation. Niklas Linde: Conceptualization, Methodology, Supervision, Writing, Supervision, Writing - original draft, Writing - review \& editing. Laurent Longuevergne: Supervision. Olivier Bour: Writing - review \& editing, Conceptualization, Writing - review \& editing.

\section{DECLARATION OF COMPETING INTEREST}

The authors declare that they have no known competing financial interests or personal relationships that could have influenced the work reported in this paper. 
682

683

684

685

686

687

688

689

690

691

692

693

694

695

696

697

698

699

700

701

702

703

704

705

706

707

\section{REFERENCES}

Alumbaugh, D.L., Newman, G.A., 2000. Image appraisal for 2-D and 3-D electromagnetic inversion. Geophysics 65, 1455-1467.

Bakker, M., Caljé, R., Schaars, F., van der Made, K., de Haas, S., 2015. An active heat tracer experiment to determine groundwater velocities using fiber optic cables installed with direct push equipment. Water Resour. Res. 51, 2760-2772.

Ballard, S., G.T. Barker, R.L. Nichols, 1996, A test of the in situ permeable flow sensor at Savannah River, South Carolina, Groundwater, volume 34, number 3, pages 389-396.

Berg, S.J., Illman, W.A., 2015. Comparison of hydraulic tomography with traditional methods at a highly heterogeneous site. Groundwater 53, 71-89.

Berg, S.J., Illman, W.A., 2013. Field study of subsurface heterogeneity with steady-state hydraulic tomography. Groundwater 51, 29-40.

Berg, S.J., Illman, W.A., 2011. Three-dimensional transient hydraulic tomography in a highly heterogeneous glaciofluvial aquifer-aquitard system. Water Resour. Res. 47(10).

Bohling, G.C., Butler Jr, J.J., 2010. Inherent limitations of hydraulic tomography. Groundwater 48, 809824.

Bohling, G.C., Butler Jr, J.J., Zhan, X., Knoll, M.D., 2007. A field assessment of the value of steady shape hydraulic tomography for characterization of aquifer heterogeneities. Water Resour. Res. 43, 6061.

Brauchler, R., Hu, R., Dietrich, P., Sauter, M., 2011. A field assessment of high-resolution aquifer characterization based on hydraulic travel time and hydraulic attenuation tomography. Water Resour. Res. 47(3).

Brauchler, R., Hu, R., Hu, L., Jiménez, S., Bayer, P., Dietrich, P., Ptak, T., 2013. Rapid field application of hydraulic tomography for resolving aquifer heterogeneity in unconsolidated sediments. Water Resour. Res. 49, 2013-2024.

Brauchler, R., Hu, R., Vogt, T., Al-Halbouni, D., Heinrichs, T., Ptak, T., Sauter, M., 2010. Cross-well slug 
interference tests: An effective characterization method for resolving aquifer heterogeneity. J. Hydrol. 384, 33-45.

Brauchler, R., Liedl, R., Dietrich, P., 2003. A travel time based hydraulic tomographic approach. Water Resour. Res. 39(12).

Butler Jr, J.J., McElwee, C.D., Bohling, G.C., 1999. Pumping tests in networks of multilevel sampling wells: Motivation and methodology. Water Resour. Res. 35, 3553-3560.

Cardiff, M., Bakhos, T., Kitanidis, P.K., Barrash, W., 2013. Aquifer heterogeneity characterization with oscillatory pumping: Sensitivity analysis and imaging potential. Water Resour. Res. 49, 5395-5410.

Cardiff, M., Barrash, W., 2011. 3-D transient hydraulic tomography in unconfined aquifers with fast drainage response groundwater flow parameters ( primarily, hydraulic conductivity $\mathrm{K}$ ) in permeable, unconfined aquifers. To invert the large amount of transient data collected from 3DT 47(12). https://doi.org/10.1029/2010WR010367

Cardiff, M., Barrash, W., Kitanidis, P.K., Malama, B., Revil, A., Straface, S., Rizzo, E., 2009. A potentialbased inversion of unconfined steady-state hydraulic tomography. Groundwater 47, 259-270.

Day-Lewis, F.D., Singha, K., Binley, A.M., 2005. Applying petrophysical models to radar travel time and electrical resistivity tomograms: Resolution-dependent limitations. J. Geophys. Res. Solid Earth 110(8). 1-17.

del Val, L., Carrera, J., Pool, M., Martinez, L., Casanovas, C., Bour, O., \& Folch, A. (2021). Heat dissipation test with fiber-optic distributed temperature sensing to estimate groundwater flux. Water Resources Research, 57, e2020WR027228. https://doi.org/10.1029/2020WR027228

Devlin, J.F., 2020, Groundwater Velocity. The Groundwater Project, Guelph, Ontario, Canada.

des Tombe, B.F., Bakker, M., Smits, F., Schaars, F., van der Made, K., 2019. Estimation of the variation in specific discharge over large depth using distributed temperature sensing (DTS) measurements of the heat pulse response. Water Resour. Res. 55, 811-826.

Doro, K.O., Cirpka, O.A., Leven, C., 2015. Tracer tomography: Design concepts and field experiments using heat as a tracer. Groundwater 53, 139-148.

Drost, W., Klotz, D., Koch, A., Moser, H., Neumaier, F., Rauert, W., 1968. Point dilution methods of 
investigating ground water flow by means of radioisotopes. Water Resour. Res. 4, 125-146.

Fakhreddine, S., Lee, J., Kitanidis, P.K., Fendorf, S., Rolle, M., 2016. Imaging geochemical heterogeneities using inverse reactive transport modeling: An example relevant for characterizing arsenic mobilization and distribution. Adv. Water Resour. 88, 186-197.

Fienen, M.N., Clemo, T., Kitanidis, P.K., 2008. An interactive Bayesian geostatistical inverse protocol for hydraulic tomography. Water Resour. Res. 44(12).

Fischer, P., Jardani, A., Soueid Ahmed, A., Abbas, M., Wang, X., Jourde, H., Lecoq, N., 2017. Application of Large-Scale Inversion Algorithms to Hydraulic Tomography in an Alluvial Aquifer. Groundwater $55,208-218$.

Gottlieb, J., Dietrich, P., 1995. Identification of the permeability distribution in soil by hydraulic tomography. Inverse Probl. 11, 353-360.

Huang, S., Wen, J., Yeh, T.J., Lu, W., Juan, H., Tseng, C., Lee, J., Chang, K., 2011. Robustness of joint interpretation of sequential pumping tests: Numerical and field experiments. Water Resour. Res. 47(10).

Illman, W. a, Liu, X., Craig, A., 2008. Evaluation of transient hydraulic tomography and common hydraulic characterization approaches through laboratory sandbox experiments. J. Environ. Eng. Manag. 18, 249-256.

IIIman, W.A., Berg, S.J., Zhao, Z., 2015. Should hydraulic tomography data be interpreted using geostatistical inverse modeling? A laboratory sandbox investigation. Water Resour. Res. 51, 32193237.

Illman, W.A., Zhu, J., Craig, A.J., Yin, D., 2010. Comparison of aquifer characterization approaches through steady state groundwater model validation: A controlled laboratory sandbox study. Water Resour. Res. 46(4).

Jamin, P., Goderniaux, P., Bour, O., Le Borgne, T., Englert, A., Longuevergne, L., Brouyère, S., 2015. Contribution of the finite volume point dilution method for measurement of groundwater fluxes in a fractured aquifer. J. Contam. Hydrol. 182, 244-255.

Jim Yeh, T., 1992. Stochastic modelling of groundwater flow and solute transport in aquifers. Hydrol. 
762

763

764

765

766

767

768

769

770

771

772

773

774

775

776

777

778

779

Process. 6, 369-395.

Jiménez, S., 2015. High resolution aquifer characterization using hydraulic tomography and tracer tomography. PhD diss., ETH Zurich, 2015.

Jiménez, S., Mariethoz, G., Brauchler, R., Bayer, P., 2016. Smart pilot points using reversible-jump Markov-chain Monte Carlo. Water Resour. Res. 52, 3966-3983.

Kang, P.K., Lee, J., Fu, X., Lee, S., Kitanidis, P.K., Juanes, R., 2017. Improved characterization of heterogeneous permeability in saline aquifers from transient pressure data during freshwater injection. Water Resour. Res. 53, 4444-4458.

Kearl, P.M., 1997. Observations of particle movement in a monitoring well using the colloidal borescope. J. Hydrol. 200, 323-344.

Klepikova, M. V, Le Borgne, T., Bour, O., de Dreuzy, J., 2013. Inverse modeling of flow tomography experiments in fractured media. Water Resour. Res. 49, 7255-7265.

Kowalsky, M.B., Finsterle, S., Rubin, Y., 2004. Estimating flow parameter distributions using groundpenetrating radar and hydrological measurements during transient flow in the vadose zone. Adv. Water Resour. 27, 583-599.

Kuhlman, K.L., Hinnell, A.C., Mishra, P.K., Yeh, T.J., 2008. Basin-scale transmissivity and storativity estimation using hydraulic tomography. Groundwater $46,706-715$.

Labaky, W., J.F. Devlin, R.W. Gillham, 2007, Probe for measuring groundwater velocity at the centimeter scale.Environmental Science and Technology, volume 41, number 24, pages 8453-8458.

Lee, J., Kitanidis, P.K., 2014. Large-scale hydraulic tomography and joint inversion of head and tracer data using the principal component geostatistical approach (PCGA). Water Resour. Res. 50, 54105427.

Lee, J., Kokkinaki, A., Kitanidis, P.K., 2018. Fast large-scale joint inversion for deep aquifer characterization using pressure and heat tracer measurements. Transp. Porous Media 123, 533543.

Lee, J., Yoon, H., Kitanidis, P.K., Werth, C.J., Valocchi, A.J., 2016. Scalable subsurface inverse modeling of huge data sets with an application to tracer concentration breakthrough data from magnetic 
resonance imaging. Water Resour. Res. 52, 5213-5231.

Lie, K.-A., 2019. An introduction to reservoir simulation using MATLAB/GNU Octave: User guide for the MATLAB Reservoir Simulation Toolbox (MRST). Cambridge University Press.

Liu, F., Yeh, T.J., Wang, Y., Hao, Y., Wen, J., Wang, W., 2020. Characterization of basin-scale aquifer heterogeneity using transient hydraulic tomography with aquifer responses induced by groundwater exploitation reduction. J. Hydrol. 588, 125137. https://doi.org/10.1016/j.jhydrol.2020.125-137

Liu, S., Yeh, T.J., Gardiner, R., 2002. Effectiveness of hydraulic tomography: Sandbox experiments. Water Resour. Res. 38, 1-5.

Liu, X., Illman, W.A., Craig, A.J., Zhu, J., Yeh, T., 2007. Laboratory sandbox validation of transient hydraulic tomography. Water Resour. Res. 43(5).

Lochbühler, T., Doetsch, J., Brauchler, R., Linde, N., 2013. Structure-coupled joint inversion of geophysical and hydrological data. Geophysics 78, ID1-ID14.

Luo, N., Illman, W.A., Zha, Y., Park, Y.-J., Berg, S.J., 2020. Three-dimensional hydraulic tomography analysis of long-term municipal wellfield operations: Validation with synthetic flow and solute transport data. J. Hydrol. 590, 125438.

Luo, N., Zhao, Z., Illman, W.A., Berg, S.J., 2017. Comparative study of transient hydraulic tomography with varying parameterizations and zonations: Laboratory sandbox investigation. J. Hydrol. 554, 758-779.

Maldaner, C.H., Munn, J.D., Coleman, T.I., Molson, J.W., Parker, B.L., 2019. Groundwater flow quantification in fractured rock boreholes using active distributed temperature sensing under natural gradient conditions. Water Resour. Res. 55, 3285-3306.

Mao, D., Yeh, T.-C.J., Wan, L., Hsu, K.-C., Lee, C.-H., Wen, J.-C., 2013. Necessary conditions for inverse modeling of flow through variably saturated porous media. Adv. Water Resour. 52, 50-61.

Michael Tso, C., Zha, Y., Jim Yeh, T., Wen, J., 2016. The relative importance of head, flux, and prior information in hydraulic tomography analysis. Water Resour. Res. 52, 3-20.

Paradis, D., Gloaguen, E., Lefebvre, R., Giroux, B., 2015. Resolution analysis of tomographic slug test 
head data: Two-dimensional radial case. Water Resour. Res. 51, 2356-2376.

Paradis, D., Lefebvre, R., Gloaguen, E., Giroux, B., 2016. Comparison of slug and pumping tests for hydraulic tomography experiments: a practical perspective. Environ. Earth Sci. 75(16), 1159.

Read, T., Bour, O., Selker, J.S., Bense, V.F., Le Borgne, T., Hochreutener, R., Lavenant, N., 2014. Activedistributed temperature sensing to continuously quantify vertical flow in boreholes. Water Resour. Res. 50, 3706-3713.

Revil, A., Karaoulis, M., Johnson, T., Kemna, A., 2012. Some low-frequency electrical methods for subsurface characterization and monitoring in hydrogeology. Hydrogeol. J. 20, 617-658.

Sayde, C., Thomas, C.K., Wagner, J., Selker, J., 2015. High-resolution wind speed measurements using actively heated fiber optics. Geophys. Res. Lett. 42, 10-64.

Schneider, H.A., Jackson, W.A., Rainwater, K., Reible, D., Morse, S., Hatzinger, P.B., Garza-Rubalcava, U., 2019. Estimation of Interstitial Velocity Using a Direct Drive High-Resolution Passive Profiler. Groundwater 57, 915-924.

Simon, N., Bour, O., Lavenant, N., Porel, G., Nauleau, B., Pouladi, B., Longuevergne, L. (2020). A Comparison of Different Methods to Estimate the Effective Spatial Resolution of FO-DTS Measurements Achieved during Sandbox Experiments. Sensors, 20(2). https://doi.org/10.3390/s20020570

Simon, N., Bour, O., Lavenant, N., Porel, G., Nauleau, B., Pouladi, B., Longuevergne, L., \& Crave, A. (2021). Numerical and Experimental Validation of the Applicability of Active-DTS Experiments to Estimate Thermal Conductivity and Groundwater Flux in Porous Media. Water Resources Research, 57(1), e2020WR028078. https://doi.org/10.1029/2020WR028078

Slater, L., 2007. Near surface electrical characterization of hydraulic conductivity: From petrophysical properties to aquifer geometries-A review. Surv. Geophys. 28, 169-197.

Somogyvári, M., Bayer, P., 2017. Field validation of thermal tracer tomography for reconstruction of aquifer heterogeneity. Water Resour. Res. 53, 5070-5084.

Soueid Ahmed, A., Jardani, A., Revil, A., Dupont, J.-P., 2016. Joint inversion of hydraulic head and selfpotential data associated with harmonic pumping tests. Water Resour. Res. 52, 6769-6791. 
Sun, R., Yeh, T.J., Mao, D., Jin, M., Lu, W., Hao, Y., 2013. A temporal sampling strategy for hydraulic tomography analysis. Water Resour. Res. 49, 3881-3896.

Tiedeman, C.R., Barrash, W., 2020. Hydraulic tomography: 3D hydraulic conductivity, fracture network, and connectivity in mudstone. Groundwater 58, 238-257.

Tosaka, H., Masumoto, K., Kojima, K., 1993. Hydropulse tomography for identifying 3-D permeability distribution, in: High Level Radioactive Waste Management: Proceedings. Volume 1, 955-959

Yeh, T.-C., Khaleel, R., Carroll, K.C., 2015. Flow through heterogeneous geologic media. Cambridge University Press.

Yeh, T.J., Liu, S., 2000. Hydraulic tomography: Development of a new aquifer test method. Water Resour. Res. 36, 2095-2105.

Yin, D., Illman, W.A., 2009. Hydraulic tomography using temporal moments of drawdown recovery data: A laboratory sandbox study. Water Resour. Res. 45(1).

Zha, Y., Yeh, T.-C.J., Mao, D., Yang, J., Lu, W., 2014a. Usefulness of flux measurements during hydraulic tomographic survey for mapping hydraulic conductivity distribution in a fractured medium. Adv. Water Resour. 71, 162-176.

Zha, Y., Yeh, T.J., Illman, W.A., Onoe, H., Mok, C.M.W., Wen, J., Huang, S., Wang, W., 2017. Incorporating geologic information into hydraulic tomography: A general framework based on geostatistical approach. Water Resour. Res. 53, 2850-2876.

Zha, Y., Yeh, T.J., Illman, W.A., Zeng, W., Zhang, Y., Sun, F., Shi, L., 2018. A reduced-order successive linear estimator for geostatistical inversion and its application in hydraulic tomography. Water Resour. Res. 54, 1616-1632.

Zha, Y., Yeh, T.J., Mao, D., Yang, J., Lu, W., 2014b. Advances in Water Resources Usefulness of flux measurements during hydraulic tomographic survey for mapping hydraulic conductivity distribution in a fractured medium. Adv. Water Resour. 71, 162-176. https://doi.org/10.1016/j.advwatres.2014.06.008

Zhao, Z., Illman, W.A., 2021. On the importance of considering specific storage heterogeneity in hydraulic tomography: Laboratory sandbox and synthetic studies. J. Hydrol. 593, 125874. 
870

871

872

Zhao, Z., Illman, W.A., 2018. Three-dimensional imaging of aquifer and aquitard heterogeneity via transient hydraulic tomography at a highly heterogeneous field site. J. Hydrol. 559, 392-410.

Zhao, Z., Illman, W.A., Berg, S.J., 2016. On the importance of geological data for hydraulic tomography analysis: Laboratory sandbox study. J. Hydrol. 542, 156-171.

Zhu, J., Yeh, T.-C.J., 2005. Characterization of aquifer heterogeneity using transient hydraulic tomography. Water Resour. Res. 41(7). 